\title{
Testing the New Keynesian Phillips curve: a frequency domain approach
}

\author{
Luca Bindelli* Université de Lausanne \\ 17 May $2005^{\dagger}$
}

\begin{abstract}
We propose a new test of the forward-looking Phillips curve for a panel of 10 OECD countries. Structural parameter estimates are obtained using an extremum estimation method which is applied in the frequency domain. Such an estimator has the advantage of enabling the econometrician to focus on subsets of frequencies for which the model is specifically designed. For most countries, and once we control for a lagged inflation term, we find that the majority of the price setters are 'backward looking'. In addition, our evidence is compatible with the hypothesis that prices are adjusted according to a fixed, time invariant pricing rule.
\end{abstract}

Keywords: Inflation, New Keynesian Phillips curve, Generalized Spectral Estimation.

JEL Classification: E31, E32, E37, C52.

\footnotetext{
*Universite de Lausanne, Ecole des HEC, BFSH1, CH-1015 Lausanne. E-mail: luca.bindelli@unil.ch

${ }^{\dagger}$ I wish to thank Andreas Fischer, Aleksandar Georgiev, Alberto Holly, Jean Imbs, Eric Jondeau as well as participants to the "Theories and Methods in Macroeconomics" conference at ENS (Lyon, January 2005) for comments and discussions. The usual disclaimer applies.
} 


\section{Introduction}

\section{$1.1 \quad$ Summary}

The purpose of this paper is to bring additional evidence to the existing literature on the forward-looking Phillips curve (FLPC) using a new econometric methodology and an expanded dataset. A common method used in the recent literature to assess the fit of the FLPC can be described as follows: first, structural parameters are estimated through GMM techniques. Second, exploiting the forward-looking nature of the standard New Keynesian Phillips curve (relating inflation to an actualized stream of future expected marginal costs), a forecasting VAR containing variables available at time $t$ to the observer is estimated to generate forecasts for the marginal costs. Using the estimated parameters and forecasts, one is then able to compute the theoretical path of inflation. ${ }^{1}$

Because of poor small sample properties, GMM estimators are often considered as lacking robustness. Moreover, GMM estimates are also found to be very sensitive to normalization (i.e. the way orthogonality conditions are imposed) and instrument specification. $^{2}$ Second, time domain estimators, such as GMM or ML, offer a 'diagnosis' of the model at hand for the entire data frequency band. By definition, it is thus not possible to disentangle effects of specific sets of frequencies over the model's performance, which is a drawback of this approach as one wishes to focus on a spe-

\footnotetext{
${ }^{1}$ This is the methodology used by Galí and Gertler (1999), Galí, Gertler and Lopez-Salido (2001) and Balakrishnan and Lopez-Salido (2002).

${ }^{2}$ See Ma (2002) or Fuhrer et al. (1995b) for examples of these issues.
} 
cific subset of frequencies for which the model is specifically designed (i.e. business cycle frequencies). Hence, an estimator allowing for a decomposition in the frequency domain could be particularly useful in testing specific features of a model. One could then potentially highlight which frequencies are responsible for a model's failure or success. ${ }^{3}$

This paper will concentrate on the potential problems related to the estimation approach. The Generalized Spectral Estimation (GSE) we use in this paper also exploits a model's moment properties but uses lagged residuals instead of endogenous variables as valid 'instruments'. The main idea is that the unexplained dynamics of a rational expectation model form a white noise process. The latter has a very simple spectral shape which can be exploited as the basis for a frequency domain extremum estimator that would minimize a function of the spectrum of the residuals. Model parameters are then estimated using a criterion function, the objective of which is to make residuals as close as possible to a white noise process. Moreover, using GSE does not require the specification of any instrument set. Importantly, this method

\footnotetext{
${ }^{3}$ Arguably, there might be a another difficulty in this literature: the tests suggested above require us to specify a forecasting VAR. Consequently, direct tests of the present value relation implied by the FLPC are always conditional on the VAR used to predict marginal cost. Forecasts are specified within the context of a fixed joint distribution between marginal costs and the forecasting variables. As demonstrated recently by Kurmann (2004), this methodology entails considerable uncertainty. Moreover, the performance of the New Keynesian Phillips curve crucially depends on the forecasting process for the marginal cost.
} 
allows estimation over subsets of frequencies. It is thus possible to determine which frequencies are responsible for the results. In contrast to the Hodrick-Prescott filtering of the variables, GSE will not alter the cyclical properties of the series. Finally, normalization plays no role when GSE is used, precisely because lagged residuals are used as 'instruments' instead of lagged endogenous variables.

\subsection{Literature and results overview}

A substantial amount of empirical literature has recently tested the fit of the New Keynesian Phillips curve. Dating back to Fuhrer and Moore (1995), several papers have cast doubt on the relevance of the FLPC, and have suggested that the inclusion of lagged inflation terms is needed to cope with the data. Jondeau and Le Bihan (2001) produce estimates of a hybrid Phillips curve for several European countries, the Euro area, and the US, and find that roughly half of the price setters set current prices with reference to past inflation levels. Roberts (2001) finds similar results for the US. Rudd and Whelan (2001) also conclude that the FLPC cannot account for observed inflation behavior. However, Galí and Gertler (1999) and Galí, Gertler and Lopez-Salido (2001) have found substantial evidence in favour of the FLPC. They estimate a hybrid Phillips curve in which both forward and backward-looking terms appear and conclude that the parameter-capturing backward-looking behavior is statistically significant but small for the US and not significant for the Euro area. In addition, they document that the marginal cost based Phillips curve can provide 
reasonable account of the post-war data features, notably of persistence properties. Sbordone (2002) obtains very similar results for the US. ${ }^{4}$ In Bindelli (2005), we study inflation's inertial properties in a panel of industrial countries by questioning the present value relation implied by the Phillips curve. This paper finds that, conditional on an autoregressive process in marginal cost, the Phillips curve is compatible with empirical evidence on persistence properties for the US but also finds that for several other European countries, the FLPC might imply too much inertia in inflation. This suggests that even though lagged inflation has been found to be significant in several previous studies, it may not be needed to generate observed inflation inertia. ${ }^{5}$ In summary, the issue remains open, and we will try to contribute to this literature by bringing new econometric evidence for an extended panel of OECD countries.

Our findings can be summarized as follows: throughout the spectrum, the FLPC is successful in the case of France and the US. Australia, Canada, and the UK are reasonably successful once we abstract from high frequencies or if we detrend both inflation and marginal cost using an H-P filter. For Austria, Germany, Italy, Japan

\footnotetext{
${ }^{4}$ Her methodology differs somewhat from Galí et al. (1999, 2001). She relies on a forecasting VAR technique but bases her forecast on a two- variables model, using unit labor cost and price/cost ratio. She then estimates parameters using a criterion function that minimizes the distance between the model and the data. The methodological difference here is that everything is plugged into the criterion function and estimated simultaneously so that one implicitly maximizes the fit of the VAR model.

${ }^{5}$ This might be simply because of a highly serially correlated driving variable (or shocks affecting it) and not because of backward-looking pricing behavior.
} 
and Sweden, the FLPC is likely to be misspecified. When a lagged inflation term is controlled for, the model detects a strongly significant weight on lagged inflation of roughly $50 \%$ for all our countries. Clearly, for some of our countries, this is hardly compatible with previous evidence in favor of a purely forward-looking model. A plausible explanation might be that a lagged inflation term is not (entirely at least) reflective of backward-looking pricing behavior. Indeed, because serially correlated shocks to the economy would imply a near observational equivalent Phillips curve to the one obtained with 'backward-looking' price setters, we cannot be sure that a hybrid Phillips curve reflects a correct specification of the price adjustment mechanism. Unfortunately, the GSE method cannot help us to distinguish between the two competing specifications. Finally, our estimates of (per period) price adjustment probability are generally stable across frequency ranges, and are thus supportive of the view that prices are updated with a fixed probability.

Our presentation starts with a short introduction to the Phillips curve. The empirical methodology is described in section 3. Section 4 contains our results. Additional robustness analysis is undertaken in section 5. A standard 'hybrid' Phillips curve is studied in section 6 . Section 7 discusses further research and concludes this study.

\section{The FLPC}

The intuition underlying the marginal cost based Phillips curve is quite simple. Firms have market power, their pricing decisions thus allowing for a markup over their 
marginal cost. Since we are in a rational expectations context, optimal prices set by firms take into account the expected evolution of marginal costs. The price-setting behavior is derived as the product of optimization by monopolistically competitive firms subject to constraints on the frequency of the price adjustment. Calvo's partial adjustment mechanism has been widely used in the literature due to its analytical tractability and we will be no exception. This time-contingent price adjustment rule stipulates that each period, firms are allowed to adjust their price with a fixed probability $1-\alpha$. The basic equation relates the actual inflation rate to the one period ahead forecasted inflation and real marginal cost:

$$
\pi_{t}=\beta E_{t} \pi_{t+1}+\psi \widehat{m c}_{t}+\varepsilon_{t}
$$

where $\pi$ is the inflation rate, $\widehat{m c}$ is the percentage deviation of average real marginal cost from its steady state level, and $\varepsilon_{t}$ is an i.i.d. error term. ${ }^{6} \beta<1$ is a subjective discount rate and $\psi=\frac{(1-\alpha)(1-\beta \alpha)}{\alpha}>0$ is interpretable as a price flexibility parameter. If a bigger fraction of firms adjusts their price, then inflation will be more sensitive to movements in marginal costs. As the probability for a firm to be able to adjust its price increases, so does $\psi$. By being able rationally to anticipate variations in their marginal cost, firms will pass through these price variations to a greater extent, since

\footnotetext{
${ }^{6}$ The equation is the result of a loglinearization of the pricing equation around a zero average inflation steady-state equilibrium level. The steady-state equilibrium level for real marginal cost level is considered to be a constant in our benchmark case analysis and will be taken as the sample mean.
} 
they have the opportunity to do so.

\section{$3 \quad$ Econometric methodology}

We will use a method sketched in Durlauf (1991) and later extended by Berkowitz (2001). These authors have suggested the use of a specific type of extremum estimator based in the frequency domain. ${ }^{7}$ The basic idea exploits the well-known result stipulating that the spectral distribution of a martingale difference sequence has the shape of a straight line.

Rational expectation models typically imply an Euler equation, which can be written as

$$
E\left[f\left(y_{t}, \theta_{0}\right) \mid I_{t}\right]=0
$$

where $f()$ is a function given by the model's first order conditions, $y_{t}$ is a vector of observable data, $\theta_{0}$ is a vector of parameter values and $I_{t}$ defines the information set available at time $t$. The above equation simply tells us that the Euler residual has a zero conditional mean. Instead of using standard GMM moment conditions, where a set of instruments is specified, the spectral-based estimation method uses the fact that, since innovations (i.e. Euler residuals) are assumed to be a martingale difference sequence, lagged residuals can be viewed as valid instruments. ${ }^{8}$ That is

\footnotetext{
${ }^{7}$ By extremum estimators, we mean estimators obtained by either maximizing or minimizing a criterion function defined over the parameter space.

${ }^{8}$ Recall that in standard GMM, rational expectation models are estimated through the assump-
} 


$$
E\left[f\left(y_{t}, \theta_{0}\right) f\left(y_{t-i}, \theta_{0}\right)\right]=0, \quad i=1,2,3, \ldots
$$

Under these conditions, it is easily verified that the spectral density $s_{f\left(y_{t}, \theta_{0}\right)}(\omega)$ is a constant over $\omega \in[-\pi, \pi] .{ }^{9}$ It follows that the spectral distribution is a straight line given by $S_{f\left(y_{t}, \theta_{0}\right)}(\omega)=\int_{0}^{\delta} s_{f\left(y_{t}, \theta_{0}\right)}(\omega) d \omega=\frac{\delta}{2 \pi} \sigma_{f}^{2}$, where $\sigma_{f}^{2}$ denotes the variance of $f\left(y_{t}, \theta_{0}\right)$. The GSE estimator can be viewed as an estimator making the residuals as close as possible to a martingale difference sequence. It is defined as

$$
\widehat{\theta}_{G S E}=\arg \min _{\theta} Q_{T}(\theta)
$$

where $Q_{T}(\theta)=\int_{\widetilde{\omega}} C_{\omega}\left(\widehat{S}_{f\left(y_{t}, \theta_{0}\right)}(\omega)\right)$ and $C_{\omega}()$ is a loss function with $\widetilde{\omega}$ representing the set of frequencies possibly included in the estimator. If, for example, we wish to focus on fluctuations of business cycle periods (32 to 6 quarters periods), we may restrict $\widetilde{\omega}=[\pi / 16, \pi / 4]$. Given the finite set of observation $T$, a maximum of $T / 2$ distinct frequencies can be calculated. These are given by $\omega_{i}=2 \pi i / T$, for $i=0, . .(T / 2)-1 .{ }^{10}$ Consistent estimates can be obtained when we try to make residuals as close as possible to a martingale difference sequence. Berkowitz (2001) proves the consistency tion that innovations are independent of past endogenous variables, which gives rise to the usual moment conditions.

${ }^{9}$ The spectral density function of a variable $x$ is given by $s_{x}(\omega)=(2 \pi)^{-1} \sum_{k=-\infty}^{\infty} \gamma_{x}(k) e^{-i \omega k}$, $\omega \in[-\pi, \pi]$ and $\gamma_{x}(k)$ is the autocovariance at lag $k$. In what follows, we limit our attention to the range $[0, \pi]$ because spectral density is symmetric around $\pi$.

${ }^{10}$ The corresponding period cycle length is given by $p_{i}=2 \pi / \omega_{i}$. 
of the estimator under some regularity assumptions. He also shows that if the loss function is twice continuously differentiable and has finite variance-covariance matrix,

$$
\sqrt{T}\left(\widehat{\theta}-\theta_{0}\right) \rightarrow N\left(0, H\left(\theta_{0}\right)^{-1} \sum H\left(\theta_{0}\right)^{-1}\right)
$$

where $H\left(\theta_{0}\right)$ is the Hessian of the minimand and $\sum=\lim T^{-1}\left(\left.\frac{\partial Q_{T}(\theta)}{\partial \theta}\right|_{\theta_{0}}\right)\left(\left.\frac{\partial Q_{T}(\theta)}{\partial \theta^{\prime}}\right|_{\theta_{0}}\right) \cdot{ }^{11}$ If one writes the partial cumulative of the distance between the (normalized) spectral density of $f()$ and the martingale spectral density, we obtain:

$$
U(\widetilde{\omega})=\int_{\omega_{i} \in \widetilde{\omega}}\left(\frac{s_{f\left(y_{t}, \theta\right)}(\omega)}{\sigma_{f}^{2}}-\frac{1}{2 \pi}\right) d \omega, \lambda_{u}, \lambda_{l} \in[0 ; 1], \text { with } \lambda_{u}>\lambda_{l}
$$

where the parameter $\widetilde{\omega}$ defines a subset of frequency bands (included between $[0, \pi]$ ). The sample counterpart of $U(\widetilde{\omega})$, denoted $\widehat{U}(\widetilde{\omega})$, should be equal to zero in expectation if $f\left(y_{t}, \theta_{0}\right)$ is a martingale difference sequence. ${ }^{12}$ In order to construct estimators based on the deviations expressed above, we only need to specify a convex loss function. For example, we will use an estimator defined as

$$
\widehat{\theta}=\arg \min _{\theta} \int_{\widetilde{\omega}} \widehat{U}^{2}(\widetilde{\omega}) d \omega .
$$

\footnotetext{
${ }^{11}$ See Berkowitz (2001) for details. The author also notes that the GSE estimator has an equivalent GMM estimator (in the time domain) which sets residuals' autocorrelations as close as possible to zero.

${ }^{12}$ Note that $U(\lambda)$ can simply be interpreted as the cumulated deviations of spectral densities (spectra). As emphasized by Durlauf (1991), the cumulated deviations of periodogram ordinates will converge to the cumulated deviations of spectra due to the law of large numbers which arises from averaging. Periodograms can thus be used in place of consistent estimates of the spectrum.
} 
We then implement a grid-search procedure throughout the parameter space. ${ }^{13}$

\section{Empirical findings}

The data used (covering the period 1970:1 to 1999:4) is described in the appendix. Our chosen metric for the marginal cost is the unit labor cost; this is to preserve the comparability of our results with previous studies. Since our sample period contains 120 observations, we can identify a maximum of 60 distinct frequencies. The FLPC model is designed to fit business cycle frequencies, i.e. cycle periods of roughly 6 to 32 quarters. Within our dataset, low frequencies are only identified for corresponding period cycles of 120, 60, 40 and 30 quarters. We therefore have decided to truncate our lowest business cycle frequency at 30 quarters, and our corresponding business cycle frequency range is defined as cycle periods of 30 to 6 quarters (frequency range $[\pi / 15, \pi / 3])$. In order to check for the stability of our parameter estimates within this range of business cycle frequencies, we also present results for cycle periods ranging between 30 and 8 quarters periods (frequency range $[\pi / 15, \pi / 4]$ ). Finally, in order to analyze the impact of low and high frequency components on our estimates, we run GSE estimation over the frequency band $\left[0, \omega_{\max }\right]$, where $\omega_{\max }=\pi / 3$ and $\pi$, corresponding respectively to a cycle period of 6 and 2 quarters. Thus, we present four frequency intervals and the corresponding estimates using GSE.

\footnotetext{
${ }^{13}$ We use a Matlab constrained minimization algorithm (fmincon.m) as well as Chris Sims' unconstrained one. Sim's optimization library is available at: http://sims.princeton.edu/yftp/optimize/.
} 


\subsection{Benchmark case}

\subsubsection{Reduced Form Estimates}

Results using GSE are presented in Table 1. For each country, we briefly discuss in turn: the whole frequency band estimator, i.e. $[0, \pi]$; the $[0, \pi / 3]$ band estimator that excludes frequencies corresponding to cycle periods of less than 6 quarters; the $[\pi / 15, \pi / 3]$ band-obtained estimates that highlight business cycle frequency range; and finally the $[\pi / 15, \pi / 4]$ band estimator.

For Australia, estimates for $\psi$ are always positive, but only significantly so in the case of the $[0, \pi]$ band estimator. All estimates are stable across the frequency bands. The results vary more for Austria. Excluding high frequencies increases $\psi$ estimates significantly (these also become significantly positive). The same is true if we exclude the lowest frequencies (as we step from $[0, \pi / 3]$ to $[\pi / 15, \pi / 3]$ band estimator). The magnitude of the $\beta$ estimates is somewhat high as low frequencies are excluded but the standard errors are wide in these cases. While $\beta$ estimates for Canada are stable across frequency bands, $\psi$ estimates also increase as high frequencies are excluded, but the parameters always remain statistically insignificant in this case. For France, the discount factor and the price flexibility parameters (always significantly positive) remain fairly stable across our frequency bands. However, $\psi$ estimates slightly increase as high frequencies are excluded. Germany and Italy do not display significantly positive estimates of $\psi$ at any frequency band: these estimates are generally very close to zero and negative. Japan displays small but positive parameter estimates for $\psi$ 
(still not significant) that increase once we exclude the highest frequencies. The same holds true for Sweden and the UK. Finally, for the US, we find stable and positive $\psi$ estimates that increase once we exclude the lowest frequencies. This increase is, however, small and all parameters are not significantly different from zero (except for the $[0, \pi]$ band).

In order to compare our results with conventional estimation methods, we have displayed in Table 2 reduced form parameter estimates obtained with GMM. We use 4 lags in inflation and marginal cost, and 2 lags in H-P detrended output as instruments. ${ }^{14} \psi$ estimates in this case are only significantly positive for Austria and the UK. We find a significant negative value for the US. For the remaining countries, estimates are very small. We never reject the overidentifying restrictions based on our J-statistics. ${ }^{15}$ If we compare these with GSE results (containing the entire frequency band), we do not observe much difference. The only exceptions are Austria and the UK, for which $\psi$ are small and not significantly different from zero, and the US, for which we find a positive and significant estimate. Concerning the discount factor, results are very similar between the two estimation methods, but estimates are higher for Japan and the UK, while lower for the US when we use GMM.

To sum up, when GSE is used, estimates for $\psi$ are generally positive throughout the frequency range, but these are small in magnitude and not significantly differ-

\footnotetext{
${ }^{14}$ For all our GMM estimations, we use Newey-West autocorrelation robust variance covariance matrices (bandwidth $\mathrm{L}=4$ ). J-statistics are also presented in the tables.

${ }^{15}$ The p-values for Austria and the US are, however, somewhat low.
} 
ent from zero. These estimates are sometimes even negative for Germany, Italy and Sweden in contradiction to the theory. Only Australia, Austria, France and US display significantly positive estimates for $\psi$ depending on the included frequencies. Overall, estimates for $\psi$ increase as the highest frequencies are excluded. For several countries, this is also true when we the lowest frequencies, as we compare GSE results for $[0, \pi / 3]$ and $[\pi / 15, \pi / 3]$ bands. GMM estimations confirm the relatively poor performance of the FLPC, with the exception of Austria and the UK. Nevertheless, comparing GSE results with GMM suggests that econometric methods enabling concentration on business cycle frequencies might well be relevant when testing the Phillips curve.

As a last remark, note that when we consider comparing our GSE estimates with traditional time domain estimators, it is likely that high frequencies would have a larger 'weight' in the GSE since more of them are identified within the cumulated spectra measure. ${ }^{16}$ In some sense, our estimator might overweight high frequency spectral densities contribution. On the other side, traditional time domain estimators are more dominated by low frequencies since spectra have often peaks at low frequencies. ${ }^{17}$ Consequently, a GSE estimator run over a subset of frequencies that

\footnotetext{
${ }^{16}$ Recall that the number of estimable frequencies is given by $\omega_{i}=2 \pi i / T$, for $i=0, \ldots(T / 2)-1$. Each spectra has a weight of one in our cumulated deviations of spectra $(U(\lambda))$.

${ }^{17}$ See Bindelli (2005) on the spectral properties of inflation and marginal cost. Similarly, Engle (1974) notes that in the case of his band spectrum estimator, estimates obtained considering low frequency spectral densities only are often comparable to estimates obtained via (full spectrum) OLS.
} 
does not contain the highest ones may also remain comparable to time domain estimators. For instance, when comparing Tables 1 and 2, GMM estimates for Austria and the UK are often closer to our GSE estimates over the $[0, \pi / 3]$ band. Performing GSE remains obviously important since this estimator identifies the set of frequencies included (or excluded) in the estimator. This cannot be done using time domain econometric methods such as GMM instead.

\subsubsection{Structural Estimates}

In Table 3, we present estimates for $\alpha$, the probability of non-adjustment, $\psi=$ $\frac{(1-\alpha)(1-\beta \alpha)}{\alpha}$ and the expected time between price changes given by $D=\frac{1}{1-\alpha} \cdot{ }^{18}$ In the German and Italian case, estimates of the probability of non-adjustment are often bigger than one throughout the considered frequency bands, implying negative probabilities of adjustment and price duration estimates of the wrong sign. The US, UK and France display significantly positive $\alpha$ estimates that decrease slightly (sometimes significantly) when we exclude high as well as low frequencies that are outside the business cycle band. Our estimated time duration between price changes for France is included between 6.8 and 9.8 quarters, and between 6.1 and 8.3 quarters for the US, depending on the frequency band considered. These results are compatible with previous empirical findings for the US. For instance, Galí et al. (2001) obtain respectively 6.5 to 7.4 quarters duration, depending on the normalization of their

\footnotetext{
${ }^{18}$ Structural parameter estimations imply very similar results compared to the reduced form estimates obtained for $\beta$ and $\psi$. Therefore, we will not discuss them further here.
} 
moment conditions. These authors also produce an estimate for the Euro zone that is included between 10.4 to 12.2 quarters. ${ }^{19}$ For nearly all frequency bands considered, Austria, Japan and Sweden's estimates for $\alpha$ are positive but not significantly different from one. In addition, a negative probability of price adjustment is found when all frequencies are included. Non-adjustment Probability estimates slightly decrease as the lowest frequencies are excluded.

Many authors have argued that the probability of price adjustment should be, for the sake of realism, time variant. Moreover, it is sometimes argued that the probability of changing prices in a given period should increase as the elapsed time since the last price adjustment increases. Then, one should observe a lower expected price duration as higher frequency components (i.e. short cycle periods) are excluded, because we expect precisely a higher probability of adjustment when lower frequency bands are considered. ${ }^{20}$ In contrast, Calvo's pricing model stipulates that prices are adjusted with a fixed probability per given unit of time (i.e. period) independently of the time the last adjustment was made, hence of the periodicity at which it is measured. ${ }^{21}$ Thus, a stable value of $\alpha$ across the measured frequencies (periodicities) is directly interpretable as being favorable to the Calvo pricing model hypothesis. To

\footnotetext{
${ }^{19}$ Their Euro area data is gathered for Belgium, Germany, Spain, France, Ireland, Italy, Luxembourg, Netherlands, Austria, Portugal and Finland. Data is then aggregated using a GDP based weighting vector.

${ }^{20}$ Recall that expected price duration is the inverse of the adjustment probability.

${ }^{21}$ Then, one should also measure a unique and stable expected price duration independently of the cycle periods.
} 
analyze this issue, we test if $\alpha$ estimates obtained with a $[\pi / 15, \pi / 4]$ band are equal to those obtained with a $[\pi / 15, \pi / 3]$ band. ${ }^{22}$ In other words, we test the hypothesis that $\alpha$ remains stable within business cycle frequencies. More formally, our simple testing experiment proceeds as follows:

$$
\begin{array}{ll}
H_{0}: & \alpha_{[\pi / 15, \pi / 4]}=\alpha_{[\pi / 15, \pi / 3]} \\
H_{1}: & \alpha_{[\pi / 15, \pi / 4]} \neq \alpha_{[\pi / 15, \pi / 3]}
\end{array}
$$

We can form the $95 \%$ confidence interval as:

$$
\widehat{\alpha}_{[\pi / 15, \pi / 4]}-1.96 \text { s.e. }\left(\widehat{\alpha}_{[\pi / 15, \pi / 4]}\right)<\alpha_{[\pi / 15, \pi / 4]}<\widehat{\alpha}_{[\pi / 15, \pi / 4]}+1.96 \text { s.e. }\left(\widehat{\alpha}_{[\pi / 15, \pi / 4]}\right)
$$

$H_{0}$ is rejected whenever $\alpha_{[\pi / 15, \pi / 4]}$ exceeds the critical value 1.96 , i.e. whenever:

$$
n=\left|\frac{\widehat{\alpha}_{[\pi / 15, \pi / 4]}-\alpha_{[\pi / 15, \pi / 3]}}{\text { s.e. }\left(\widehat{\alpha}_{[\pi / 15, \pi / 4]}\right)}\right|>1.96 .
$$

Excluding Canada, we never reject $H_{0}$ based on a confidence interval level of $95 \%{ }^{23}$ Consequently, the Calvo pricing adjustment mechanism that underlies the FLPC might be a good first approximation of a firm's pricing behavior.

To sum up, evidence in favor of the FLPC is reasonably good in the case of France and the US when we focus on structural estimates. The cases of Germany and Italy

\footnotetext{
${ }^{22}$ To perform the test, we assume that $\alpha_{[\pi / 15, \pi / 3]}$ estimates represent the "true value" to be tested. We could have done this the other way round but the conclusions presented here would not have changed.

${ }^{23}$ We find the following values for $n$ : Australia, 0.01; Austria, 0.38; Canada, 3.75; France, 0.89; Germany, 1.47; Italy, 0.01; Japan, 0.10; Sweden, 0.07; UK, 1.20; US, 0.10.
} 
clearly indicate a misspecification of the FLPC. For the remaining countries it is also likely that the Phillips curve is misspecified. In fact, although $\psi$ estimates are generally positive, they are not significantly different from zero. Finally, the Calvo pricing mechanism is possibly a good device for modeling pricing behavior. In the next sections, we will explore further marginal cost measurement as well as pricing functional form issues.

\section{Robustness analysis}

We conduct two types of alternative specifications of the original FLPC. One focuses on trend and high frequency related aspects in both inflation and marginal cost. The second concentrates on an alternative measure of marginal cost.

\subsection{Hodrick-Prescott detrending}

The assumption of a constant trend around which both inflation and marginal cost fluctuate is potentially an oversimplification given that during our sample period, there happen to have been several types of shocks or structural changes which might have affected these variables. In other words, the assumed constant trends do not en-

tirely capture low frequency components. At the other end of the spectrum, and due in part to its composite structure, we cannot exclude that our measure of marginal cost might also potentially entail some noisy component, leading eventually to observed spurious results for some countries. GSE estimation, run over relevant subsets 
of frequency bands, allows us to deal with such problems. Researchers have, however, usually employed another way: the data might be filtered to start with, so that the detrended variable's frequency properties will be modified from the very beginning of the analysis.

In this section, as has been widely used in the literature, we apply a HodrickPrescott (H-P) filter to our series so as to concentrate on a 6-32 quarter periodicity of the variables. ${ }^{24}$ The direct filtering of low as well as high frequencies in the data makes the GSE estimates lose somewhat of their appeal. In fact, since the data is already prefiltered, GSE may now be used as a time domain estimator to the extent that we shall now consider estimates for the entire frequency band. Note that a GSE estimation of the model over the whole frequency band with a H-P filtering of the variable is not equivalent to GSE estimation run over the frequencies corresponding to a 6-32 quarter periodicity interval. In the latter case, there is no need to extract a cyclical series from the beginning. This is an important difference to note since an ideal filter should precisely extract a specific range of periodicity without altering the properties of the extracted component. In that respect, GSE estimates are 'neutral'. In contrast, as Guay and St Amant (1997) and others have shown, the H-P filter performs poorly in terms of extracting business cycle frequencies if the peak of the series' spectral density occurs at low frequencies, which is precisely the case of most macroeconomic series. Moreover, it tends to amplify cycles at business-cycle frequencies in

\footnotetext{
${ }^{24}$ We set $\lambda$, the smoothing parameter, equal to 1600 as conventionally done for quarterly data.
} 
the detrended data and to dampen long-run and short-run fluctuations. Hence, H-P filtered variables could potentially lead to spurious results. We nonetheless decide to pursue the experiment due to the widespread use of such methods, and the possibility left to us to compare the relative performance of the GSE estimator.

The GSE structural estimates are reproduced in Table 4. At first glance, parameter estimates for Australia are more plausible compared with our mean detrended variable obtained estimates using the $[\pi / 15, \pi / 3]$ band (our benchmark). The rigidity parameter estimate is now higher, and a plausible price duration estimate of roughly 5 quarters is obtained. For Canada, the discount factor estimate is roughly equal to one while $\psi$ is small and not significantly different from zero. $D$ is estimated to be quite large at nearly 13 quarters. In the Austrian and French cases, $\beta$ estimates are estimated to be above one, although not significantly so, but $\psi$ estimates are positive and significant. A realistic estimate of 4 quarters price duration is obtained. The fit for Germany and Italy does not improve, and the rigidity parameters are still not significant. The results for Japan do not exhibit any improvement with respect to the benchmark case. The same comment applies to Sweden. The UK estimation results suggest parameter values which are very close to our estimates in the benchmark case, where the rigidity parameter estimate is, again, not significant. In the case of the US, the estimation identifies a period of rigidity which decreases from 6.1 to 5.6 quarters compared to the benchmark case. To sum up, this evidence supports the relative success of the FLPC for France and the US, with positive and significant 
estimates for $\psi$. In the case of Austria, we suspect that some high frequency noise might indeed affect the relationship between inflation and marginal cost. In fact, estimates of $\psi$ in Table 4 are generally close to estimates obtained in our benchmark case and including low frequencies in our GSE estimation does not significantly alter the estimate. On the other hand, results for Japan and Sweden do not show any significant improvement with respect to our benchmark. Finally, and with respect to the above discussion about H-P filtering properties, an increase (with respect to our benchmark) in estimated $\psi$ should be taken with care. As discussed above, because business cycle frequencies are amplified, we might capture an artificially increased correlation between inflation and marginal cost at those frequencies.

\subsection{Alternative measure of marginal cost}

In this subsection, we wish to address the issue of how sensitive the results are to an alternative specification of real marginal costs. The alternative we wish to explore here stems from the assumption that the production technology is no longer of a CobbDouglas form. Under the assumption of constant returns to scale, real marginal cost is equal to unit labor cost multiplied by the inverse of labor elasticity with respect to output. ${ }^{25}$ We assume competitive input markets, constant returns to scale as well as perfectly mobile capital across firms, so that the marginal cost is the same for all firms.

Let $K_{t}$ be the capital stock, $L_{t}$ employment, $Y_{t}$ the demand faced by a firm and $z_{t}$ a

\footnotetext{
${ }^{25}$ See Bindelli (2005), for example.
} 
labor augmenting technical progress scaling factor. The firm is a wage taker, produces according to $Y_{t}=F\left(K_{t}, z_{t} L_{t}\right)$ and solves the classical cost minimization problem. $R_{t}$ and $W_{t}$ are the nominal prices of capital and labor respectively. Writing the elasticity of output with respect to labor as $\eta_{L}=z_{t} F_{L}() \frac{L_{t}}{Y_{t}}$, we have: $m c_{t}=\frac{M C_{t}}{P_{t}}=\frac{1}{\eta_{L}} \frac{W_{t} L_{t}}{P_{t} Y_{t}}$. The real marginal cost is thus the product of the inverse labor elasticity and the labor share and $\eta_{L}$ is a function of the sole output-capital ratio. To see this last point, recall that since we assume constant returns to scale, homogeneity of degree one requires:

$$
\begin{aligned}
F\left(K_{t}, z_{t} L_{t}\right) & =z_{t} L_{t} F_{L}()+K_{t} F_{K}() \\
1 & =\eta_{L}+\eta_{K} .
\end{aligned}
$$

If we now assume that $F\left(K_{t}, z_{t} L_{t}\right)$ takes the form of a CES production function, we have: $\eta_{L}=1-\lambda\left(Y_{t} / K_{t}\right)^{\theta}$. More specifically $Y_{t}=\left[\lambda\left(K_{t}\right)^{-\theta}+(1-\lambda)\left(z_{t} L_{t}\right)^{-\theta}\right]^{-1 / \theta}$, where $\theta>-1$ and $0<\lambda<1$ are respectively substitution and distribution parameters. In the case where $\theta$, the elasticity of substitution between labor and capital, is less than one, $\eta_{L}$ monotonically decreases in the output-capital ratio. Since the latter is procyclical, the marginal cost will be more procyclical than the labor share. To implement this measure of marginal cost, we need to calibrate values for $\theta$ and $\lambda$. A variety of empirical studies have produced estimates for $\lambda$, which generally range between 0.2 and 0.4 . Estimates of $\theta$ are more variable across the literature. ${ }^{26}$ We finally chose values taken from Rotemberg and Woodford (1999), who suggest $\lambda=0.3$ and $\theta=0.5$. Series on capital are generated assuming a fixed depreciation

\footnotetext{
${ }^{26}$ See Chirinko (2002) for a survey.
} 
rate. ${ }^{27}$ Following Nehru and Dareshwar (1993) (see also Nadiri and Prucha (1993)) we assume a depreciation of $4 \%$ per annum.

Figure 2 presents the unit labor cost assuming CES technology along with the unit labor cost in our benchmark case. Both series are very close to each other and we should expect resulting estimations to reflect this similarity. GSE reduced form estimates for $[0, \pi]$ and $[0, \pi / 3]$ frequency bands are reproduced in Table $5 .^{28}$ For nearly all countries, $\beta$ estimates are very close to those obtained in our benchmark case and also display very similar standard error bands. They are, however, slightly lower for the UK. Estimated $\psi$ are also very close to our benchmark case coefficients, with again the exception of the UK, for which estimates are slightly higher. Overall, structural estimate results mirror the findings on reduced parameter estimates and are very similar to those presented in Table $3{ }^{29}$

\section{Hybrid Phillips Curve}

Many authors have rejected the FLPC on the grounds that a lagged inflation term, which is not predicted by the model, is found to be significant when included. More-

\footnotetext{
${ }^{27}$ An initial level for the capital stock is also needed. We use here the perpetual inventory method and assume a constant capital-output ratio at the steady state. Moreover, capital and output grow at the same rate so that initially $K_{t}=I_{t+1} /(g+\delta)$ (assuming the standard accumulation rule $\left.K_{t}=I_{t}+(1-\delta) K_{t-1}\right)$, where $g$ is capital growth rate and $\delta$ the depreciation rate.

${ }^{28}$ Results for the remaining frequency bands are also very similar and are not displayed.

${ }^{29}$ Since these are very similar, they are not presented here.
} 
over, such a lagged inflation term would be needed to generate observed inflation persistence. In light of our findings, do we really need a lagged inflation term to generate the observed inflation dynamics? To answer this question we will make use of a hybrid Phillips curve (HPC) specification suggested by Galí and Gertler (1999). As for our model above, each firm is allowed to adjust its price with a fixed probability $1-\alpha$. The additional assumption concerns the type of firms present in the economy. There are two: a fraction $1-\omega$ of the firms set prices optimally (using all available information to forecast future marginal costs), while the remaining firms are assumed to set their prices according to a 'rule of thumb': they set prices equal to the average newly adjusted prices of the last period plus an adjustment for expected inflation, based on lagged inflation. ${ }^{30}$ As it is usually done in the literature, we will refer to these as 'forward-looking' and 'backward-looking' firms respectively. The resulting Phillips curve is given by:

$$
\pi_{t}=\gamma_{b} \pi_{t-1}+\gamma_{f} E_{t} \pi_{t+1}+\psi \widehat{m c}_{t}+\varepsilon_{t}
$$

$$
\begin{aligned}
& \text { with } \\
& \psi=(1-\omega)(1-\alpha)(1-\beta \alpha) \phi^{-1}, \\
& \gamma_{f}=\beta \alpha \phi^{-1}, \\
& \gamma_{b}=\omega \phi^{-1}, \\
& \text { and } \phi=\alpha+\omega[1-\alpha(1-\beta)] .
\end{aligned}
$$

\footnotetext{
${ }^{30}$ See Galí and Gertler (1999) for details.
} 
where $\gamma_{f}$ and $\gamma_{b}$ are parameters mainly depending on $\alpha$ and $\omega$, reflecting the overall forward-looking and backward-looking compound respectively in the Phillips curve. ${ }^{31}$ Tables 6 and 6 bis present the structural estimates of this hybrid Phillips curve when marginal cost is used as the driving process. All parameter estimates are highly significant, the only exception being the parameter $\psi$ when the entire frequency band is considered (not true for Australia and Japan). $\beta$ estimates are always bigger than one when we account for the $[0, \pi]$ frequency band. As we concentrate on business cycle frequencies, $\psi$ estimates increase and become significantly different from zero, and $\beta$ estimates shrink to more conventional values. The estimated probability of adjustment implies a price duration contained within 2.1 (US) - 3.4 (Germany) quarters, which is quite realistic. The fraction of firms updating on a 'rule of thumb' basis is always contained within the 0.52 (US) - 0.63 (Germany) interval, suggesting that a majority of the firms who are able to adjust do so with reference to past optimal prices and adjust them according to past inflation values. This proportion increases substantially if we account for the highest frequencies (i.e. $[\pi / 3, \pi]$ ), in parallel with a lower probability of adjustment which induces a longer estimated price duration. Note that a decrease in $\omega$ implies an increase in $\psi$ : this is simply because a higher fraction of firms behave in a forward-looking manner, And since these are, by definition, more sensitive to the evolution of marginal cost, $\psi$ increases. We note that the exclusion of the lowest frequencies (i.e. $[0, \pi / 15]$ ) also slightly decreases

\footnotetext{
${ }^{31}$ Note that if $\omega=0$, that is if all firms are 'forward looking', we are back to the FLPC. Also, if $\beta=1$, then $\gamma_{b}+\gamma_{f}=1$.
} 
the probability of adjustment and the probability of 'rule of thumb' behavior. This impact is mostly reflected in $\psi$ and $D$ estimates, while $\gamma_{b}$ and $\gamma_{f}$ estimates are left virtually unchanged. Importantly, we note that all our estimates remain stable, if not unchanged, within the business cycle frequency range. In fact, we never reject the null hypothesis that $\alpha_{[\pi / 15, \pi / 4]}=\alpha_{[\pi / 15, \pi / 3]}$ at a $5 \%$ confidence level. ${ }^{32}$ This suggests that a Calvo pricing framework is also a good description of the actual pricing mechanism in the case of the hybrid Phillips curve specification.

In Table 7, we present reduced form GMM estimates. The estimated fraction of backward-looking price setters is generally smaller than with GSE, although the standard errors are large in this case. The only exceptions are Italy and the US for which estimates are roughly 0.457 (with standard error of 0.060 ) and $0.413(0.055)$ respectively. In addition, we never find significant positive estimates for $\psi$. Sweden is a very peculiar case for we find a backward-looking component that is not significantly different from zero, potentially reporting all firms' pricing behavior toward a forwardlooking component. This, however, directly contradicts our findings with the FLPC. Galí et al. (2001, 2002) obtain for the US estimates for $\gamma_{b}$ ranging from 0.326 to 0.364 and $\gamma_{f}$ estimates included between 0.593 and 0.617 depending on the normalization and the instruments used, whereas we obtain 0.56. Galí et al. (2001, 2002) obtain estimates for $\psi$ close to 0.1 , which is very similar to what we obtain with GSE when concentrating on business cycle frequencies. Using GMM, Jondeau and Le

\footnotetext{
${ }^{32}$ We find the following values for $n$ : Australia, 0.75; Austria, 0.58; Canada, 0.25; France, 0.18; Germany, 0.50; Italy, 0; Japan, 0.42; Sweden, 0.75; UK, 0.31; US, 0.27.
} 
Bihan (2001) also produce estimates for a hybrid Phillips curve under the constraint $\gamma_{b}+\gamma_{f}=1$. They obtain estimates for $\psi$ for several European countries and the US. ${ }^{33}$ For Germany and the UK, their estimates are, respectively: 0.011 and 0.033 . For Italy and France, their estimates are lower than ours at -0.006 and 0.002 respectively and more in line with our own estimates. This is also true in the case of the US (0.004). As in our case, note that these authors find that none of the above estimates are significantly different from zero. Finally, their estimates for $\gamma_{b}$ are the following: for the US they obtain 0.369, Germany 0.099, France 0.384, Italy 0.491 and the UK $0.181 .^{34}$

Our GSE results presented in Tables 6 and 6 bis suggest that a substantial part of the producers update the price using a simple 'rule of thumb'. In addition, 'backwardlooking' behavior, as pointed out by $\gamma_{b}$ estimates, is found to be higher than usually found with GMM methods, and in particular higher than that which has been advocated by Galí et al. $(2001,2002)$ for the US. ${ }^{35}$ In light of these findings, sustaining that the forward-looking component in inflation dynamics dominates is arguably over-

\footnotetext{
${ }^{33}$ They use 4 lags in inflation, marginal cost, H-P detrended output, and short term interest rate as instruments.

${ }^{34}$ Interestingly, Jondeau and Le Bihan (2001) also produce estimates using Maximum Likelihood estimators. Their obtained point estimates for $\psi$ are generally higher than with GMM. Their estimates for $\gamma_{b}$ are the following: for the US they obtain 0.458, Germany 0.438, France 0.458, Italy 0.460 and the UK 0.285 .

${ }^{35}$ However, Galí et al. (1999) find values for $\omega$ up to 0.522 for one of their specifications where $\beta$ is restricted to 1 .
} 
stated for all the industrialized countries analyzed in this study. In addition, our GSE method suggests that some high frequency dynamics (not intended to be captured to start with) may well drive some spurious results, notably in the case of $\psi$ estimates, where these appear to become significantly different from zero as we exclude high frequencies from the estimation.

In Tables 8 and 8bis, we present the structural estimates of this hybrid Phillips curve when output gap is used as the driving process. ${ }^{36}$ These results also confirm that a lagged inflation term is always significant, though slightly smaller than in the marginal cost based HPC. A fixed adjustment probability is also supported in this case, as $\alpha$ estimates are stable within business cycle frequency intervals. ${ }^{37}$ At business cycle frequencies, estimates for $\gamma_{b}$ are closer to 0.5, with Austria and Sweden displaying estimates close to 0.46 . The major change concerns the generally higher value of $\psi$ and the lower price duration: the latter now ranges between 1.8 (Austria and Sweden) and 2.6 (Canada), which are even more realistic estimates. In addition, for Germany and Japan, the discount factor estimates are now lower than one. Note that estimates for the full frequency band again display $\beta$ estimates which are generally above one and $\psi$ coefficients not always significant. Importantly, and contrary to the results of Galí et al. $(1999,2001)$ for the US, we find that an output gap based

\footnotetext{
${ }^{36}$ The output gap is measured as H-P detrended output.

${ }^{37}$ We use the same hypothesis testing as previously. We find the following values for $n$ : Australia, 0.38; Austria, 0.13; Canada, 0.08; France, 0.29; Germany, 0.33; Italy, 0; Japan, 0.12; Sweden, 0.33; UK, 0.14 ; US, 0.15 .
} 
Phillips curve performs as least as well as a marginal cost based one. ${ }^{38}$ This result is somewhat surprising for it means that a labor market flexibility assumption along with a linear relation between output gap and unit labor cost yields a Phillips curve that is empirically plausible, at least to a first approximation. The addition of labor market imperfections would not be needed in this context. ${ }^{39}$

Table 9 presents our GMM estimates using H-P detrended output as the driving variable. All estimates remain very close to our findings with marginal cost based Phillips curve, and none are significantly altered. Jondeau and Le Bihan (2001) also produce GMM estimates using a H-P detrended output gap measure. Most of the time, they do not find significant parameter values for $\psi$. For Germany and Italy, their estimates are 0.058 and 0.039 respectively. For France and the UK these are respectively -0.02 and -0.138 . Again, as for their marginal cost based estimations, all these parameters are not significantly different from zero. This is also true in the case of the US (-0.039). Their estimates for $\gamma_{b}$ are also again slightly lower (except for Italy) than ours. For the US, they obtain 0.344, Germany 0.105, France 0.379, Italy 0.490 and the UK $0.171 .^{40}$

\footnotetext{
${ }^{38}$ Note that Galí et al. (1999, 2001) use a quadratically detrended output.

${ }^{39}$ Some authors have indeed argued that such an assumption would reduce the sensitivity of marginal cost to output fluctuations, thereby enhancing inflation persistence.

${ }^{40}$ Their MLE estimations also yield also higher backward-looking parameter estimates. Their estimates for $\gamma_{b}$ are the following: for the US they obtain 0.473, Germany 0.436, France 0.462, Italy 0.472 and the UK 0.418 . Concerning $\psi$, their estimation yield small estimates that are never significantly different from zero.
} 
The above results seem to confirm the views that backward-looking behavior is predominant and that it is important to abstract from the highest frequencies when testing the model. But how can we reconcile those results with the results obtained for purely forward-looking Phillips curves (for the US for example), or with the results obtained by Galí et al. (1999, 2001) and Sbordone (2002)? Moreover, as the results of Bindelli (2005) also suggest, backward-looking behavior is not needed to account for the observed inflation inertia. In particular, the simple forward-looking specification possibly generates enough persistence, if not too much. A possible explanation lies in the fact that the lagged term appearing in the hybrid Phillips curve introduces an artificial way to capture a serially correlated error term. In such a case, the model equation, though not identical, resembles the classical hybrid Phillips curve, notably because of the presence of lagged inflation. In other words, if lagged inflation appears to be important in determining present inflation, it might simply be because shocks to the economy are correlated and not because lagged inflation is itself important for the decision maker. Unfortunately, such similarities in the model specifications could pose identification problems, i.e. a potential observational equivalence may arise. More precisely, the nature of the expectational error term would be different, but neither GMM nor GSE would clearly identify it when estimating the parameters resulting from the moment conditions. Further investigation is thus needed on this matter. ${ }^{41}$

\footnotetext{
${ }^{41}$ In addition, if the true model indeed contains errors that are serially correlated, this would also mean that our parameter estimates could potentially be biased. This would also be true in the case
} 


\section{Conclusion}

We have seen that evidence on the forward-looking Phillips curve is not overall convincing. For France and the US, the performance of the FLPC is satisfactory at all frequency bands. The performance of the FLPC is relatively improved for 5 out of 10 countries once we omit high frequency bands in the estimation while for the remaining half, the FLPC is likely to be misspecified. Omitting low frequencies also slightly improves the model's performance, although the improvement is much smaller and not widespread across countries. This suggests that when testing models of the business cycle, particular care should be taken in focusing precisely on these business cycle frequencies. Once we control for the presence of a lagged inflation term, its coefficient is always significant and important in magnitude, so that less than half of the firms update their price in a forward-looking manner. Whether this result stems from 'rule of thumb' behavior is not yet clear. In addition, our study substantially differs from Galí et al. (1999, 2001) concerning the conclusions reached on the output gap based hybrid Phillips curve. Finally, we find that the relative stability of the price adjustment parameter within business cycle frequencies is supportive of a fixed adjustment probability mechanism.

We note some limitations and, accordingly, possible extensions to our analysis. First, our study did not concentrate on open economy factors. Including imported of GMM. Despite the use of autocorrelation robust variance covariance matrices, lagged instruments would be correlated with errors and estimators would also be biased. 
materials would probably be the simplest way to check for their relevance. ${ }^{42}$ Second, our results obtained with detrended output are supportive of the hybrid Phillips curve. However, the theoretical steady-state equilibrium level of output is potentially only partly captured by such simple detrending methods. A testable theory-based measure of potential output would thus be welcome for further study on this issue. Third, the friction mechanism that underlies such models deserves deeper exploration. As we have seen, the labor market flexibility underlying our driving processes might not be a bad assumption at all. Still, there is a considerable ongoing debate as to whether rigidities in the labor market are more relevant than price stickiness. A estimate of a theory-based wage adjustment equation would without doubt help distinguish between models that rely primarily on price stickiness from those that emphasize labor frictions. Finally, it is rather evident that our choice of focusing on the supply side behavior is not entirely successful at depicting the overall dynamics of inflation and leaves marginal cost (or output gap) as entirely exogenously determined. Exploring the FLPC in a fully articulated general equilibrium model with endogenous policy is desirable. Such a setup will allow deeper understanding of endogenous mechanisms at the source of marginal cost or output dynamics. In addition, we could consistently test the role of backward-looking price setting versus serial correlation in the economy.

\footnotetext{
${ }^{42}$ Balakrishnan and Lopez-Salido (2002) do this for the UK but do not find significant improvement.
} 


\section{References}

[1] Balakrisnan, Ravi, and David Lopez-Salido, 2002, "Understanding UK inflation: the role of openness.", Working Paper n²164, Bank of England.

[2] Bardsen, Gunnar, Eilev S. Jansen and Ragnar Nymoen, 2002. "Testing the New Keynesian Phillips Curve". Working Paper, Norges Bank.

[3] Battini, Nicoletta, 2002. "Euro Area Inflation Persistence." European Central Bank, Working Paper n²01.

[4] Berkowitz, Jeremy, 2001. "Generalized Spectral Estimation of the Comsumptionbased Asset Pricing Model.", Journal of Econometrics, 104, pp.269-288.

[5] Bindelli, Luca, 2005. "Is the Forward Looking Phillips Curve Unable to Generate Inflation Inertia?", University of Lausanne, mimeo.

[6] Campbell, J.Y. and R.J. Shiller, 1987. "Cointegration and Tests of Present Value Models.", Journal of Political Economy, 95, pp. 1062-1088.

[7] Chari, V.V., Patrick J. Kehoe and Ellen Mc Grattan, 2000. "Sticky Price Models of the Business Cycle: Can the Contract Multiplier Solve the Persistence Problem?" Econometrica, 68, pp. 1151-1179.

[8] Chirinko, Robert S., 2002. "Corporate Taxation, Capital Formation, and the Substitution Elasticity between Labor and Capital.” Mimeo. 
[9] Clarida, Galí and Gertler, 1999. "The Science of Monetary Policy: A New Keynesian Perspective." Journal of Economic Literature, 37(4) pp.1661-1707.

[10] Dotsey, Michael , 2002, "Pitfalls in Interpreting Tests of Backward Looking Pricing in New Keynesian Models.", Economic Quarterly, Federal Reserve Bank of Richmond, 88(1), pp.37-50.

[11] Dotsey, Michael and Robert G, King,2001. "Pricing, Production and Persistence." NBER Working Papers n 8407, Cambridge.

[12] Durlauf, Steven N., 1991, "Spectral Based Testing of the Martingale Hypothesis.", Journal of Econometrics, 50, pp.355-376.

[13] Engle, Robert F., 1974, "Band Spectrum Regression.", International Economic Review, 15(1), pp.1-11.

[14] Estrella, Arturo and Jeffrey C. Fuhrer, 1998, "Dynamic Inconsistencies: Counterfactual Implications Of a Class of Rational Expectations Models.", Federal Reserve Bank of Boston, Working paper, 98-5 .

[15] Fuhrer, Jeffrey , 1997, "The (Un)Importance of Forward Looking Behavior in Price Specifications.", Journal of Money, Credit, and Banking, 29(3), pp.338350.

[16] Fuhrer, Jeffrey and Geoffrey Moore, 1995a. "Inflation Persistence." Quarterly Journal of Economics, 110(1), pp.127-159. 
[17] —, and Scott D.Schuh, 1995b. "Estimating the Linear Quadratic Inventory Model Maximum likelihood versus GMM." Journal of Monetary Economics, 35, pp.115-157.

[18] Galí, Jordi and Mark Gertler, 1999. "Inflation Dynamics: A Structural Econometric Analysis." Journal of Monetary Economics, 44, pp.195-222.

[19] Galí, Jordi, Mark Gertler and J. David Lopez-Salido, 2001. "European Inflation Dynamics." European Economic Review, 45, pp.1237-1270.

[20] Galí, Jordi, Mark Gertler and J. David Lopez-Salido, 2001. "European Inflation Dynamics: A Correction.”, mimeo.

[21] Goodfriend, Marvin and Robert G, King,1997. "The new neoclassical synthesis and the role of monetary policy." NBER Macroeconomics Annual, vol.12, MIT Press, Cambridge.

[22] Guay, Alain, and Pierre St-Amant, 1997. "Do the Hodrick-Prescott and BaxterKing Filters Provide a Good Approximation of Business Cycles?", Working Paper $\mathrm{n}^{\circ} 53$, Université du Québec à Montreal.

[23] Hamilton, James, 1994. Time Series analysis. Princeton University Press, Princeton.

[24] Holden, Steinar, and John C. Driscoll, 2001. "A Note on Inflation Persistence". NBER Working Papers, $\mathrm{n}^{\circ} 8690$. 
[25] Jondeau, Eric, and Hervé Le Bihan, 2001, "Testing for a Forward Looking Phillips Curve. Additional Evidence from European and US data.", Notes d'Etudes et de Recherches, Banque de France, $\mathrm{n}^{\circ} 86$.

[26] King, Robert G., and Alexander L. Wolman, 1996. "Inflation targeting in a St. Louis model of the 21st century." Federal Reserve Bank of St. Louis Review, 78, pp.83-107.

[27] Kurmann, André, 2004, "Quantifying the Uncertainty about the Fit of a New Keynesian Pricing Model.", Journal of Monetary Economics, forthcoming.

[28] LeRoy, Stephen F., and Richard D. Porter, 1981. "The Present-value Relation: Tests Based on Implied Variance Bounds.”, Econometrica, 49(3), pp.555-574.

[29] Ma, Adriam, 2002. "GMM Estimation of the new Phillips Curve." Economics Letters, 76, pp. 411-417.

[30] Mankiw, Gregory, 2001. "The Inexorable and Mysterious Trade-off Between Inflation and Unemployment." The Economic Journal, 111 (May), C45-C61.

[31] Mankiw, Gregory and Ricardo Reis, 2001. "Sticky Information versus Sticky Prices: A proposal to Replace the New Keynesian Phillips Curve." NBER Working Papers, $\mathrm{n}^{\circ} 8290$. 
[32] Nadiri, Ishaq, and Ingmar R. Prucha, 1993. "Estimation of the Depreciation Rate of Physical Capital and R \& D Capital in the U.S. Total Manufacturing Sector.", NBER Working Papers n 4591, Cambridge.

[33] Nehru, Vikram, and Ashok Dareshwar, 1993. "A New Database on Physical Capital Stock: Sources, Methodology and Results.", Revista de Analisis Economico, 8(1), pp.37-59.

[34] Roberts, John M. ,1997. "Is Inflation Sticky?" Journal of Monetary Economics, 39(2), pp.173-196.

[35] Roberts, John M., 2001, "How Well does the New Keynesian Sticky-Price Model Fit the Date?", Manuscript, Board of Governors of the Federal Reserve System.

[36] Romer, David, 1993. "The new Keynesian synthesis." Journal of economic perspectives, 7 (1), pp.5-22.

[37] Rotemberg, Julio, 1996. Comment on: "Inflation targeting in a St. Louis model of the 21st century." Federal Reserve Bank of St. Louis Review, 78.

[38] Rotemberg, Julio and Michael Woodford, 1999. "The Cyclical Behavior of Prices and Costs." In Handbook of Macroeconomics, Vol.1B, Edited by J.B. Taylor and M. Woodford, Elsevier Science, Amsterdam.

[39] Rudd, Jeremy and Karl Whelan, 2001, "New Tests of the New Keynesian Phillips Curve.", mimeo. 
[40] Sbordone, Argia, 2002. "Prices and Unit Labor Costs: A New Test of Price Stickiness." Journal of Monetary Economics, 49, pp. 265-292.

[41] Shiller, Robert J., 1981. "Do Stock Prices Move Too Much to be Justified by Subsequent Changes in Dividends?" American Economic Review, 71(3), pp. 421436.

[42] Taylor, John B., 1999. "Staggered Price and Wage Setting in Macroeconomics." In Handbook of Macroeconomics, Vol.1B, Edited by J.B. Taylor and M. Woodford, Elsevier Science, Amsterdam.

[43] Taylor, John B., 2000. "Low inflation, pass-through, and the pricing power of firms." European Economic Review, 44, pp.1389-1408.

[44] Wolman, Alexander, 1999. "Sticky prices, marginal cost, and the behavior of inflation." Economic Quarterly, Federal Reserve Bank of Richmond, 85(4), pp.2948.

[45] Walsh, Carl E., 2003, "Monetary Theory and Policy.", MIT Press, 2nd edition.

[46] Woodford, Michael, 1999, "Optimal Monetary Policy Inertia.", NBER Working Paper, $\mathrm{n}^{\circ} 7261$.

[47] Woodford, Michael, 2003, "Interest and Prices.", Princeton University Press . 


\section{Appendix}

\subsection{Data}

Our dataset is quarterly and covers 10 countries from Q1:1970 to Q4:1999. The countries included in our analysis are: Australia, Austria, Canada, France, Germany, Italy, Japan, Sweden, the United Kingdom and the US. All data come either from the IMF's International Financial Statistics (IFS) or the OECD Quarterly National Accounts (QNA) databases. Inflation is taken as the Consumer Price Index quarterly percent change. Marginal cost is measured by a constructed series on unit labour cost in all economic activities. ${ }^{43}$ We use series on GDP and employee's compensation (QNA) in current prices and national currencies. Wage earnings and employment data are used to compute the labour share for Germany and Sweden, for which we have no compensation figures (QNA, indexed at 1995 value). Quarterly inflation and marginal cost series are plotted in Figure 1.

\footnotetext{
${ }^{43}$ Marginal cost measurement issues are further discussed in the appendix.
} 
Figure 1: Quarterly inflation rate (dashed line, right scale) and unit labor cost percentage deviation from sample mean (solid line, left scale).
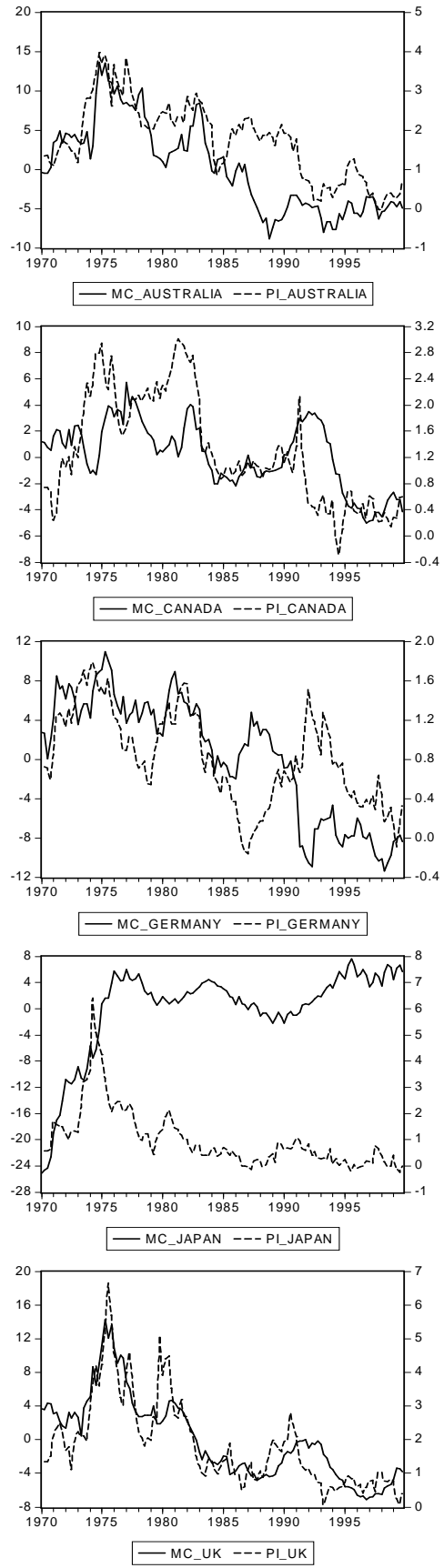

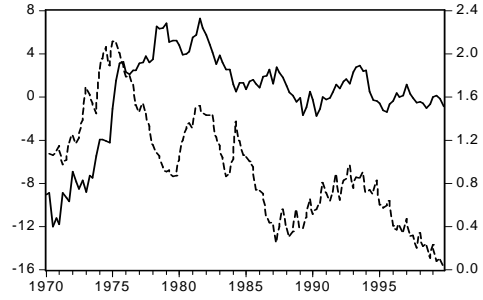

-MC_AUSTRIA ----PI_AUSTRIA
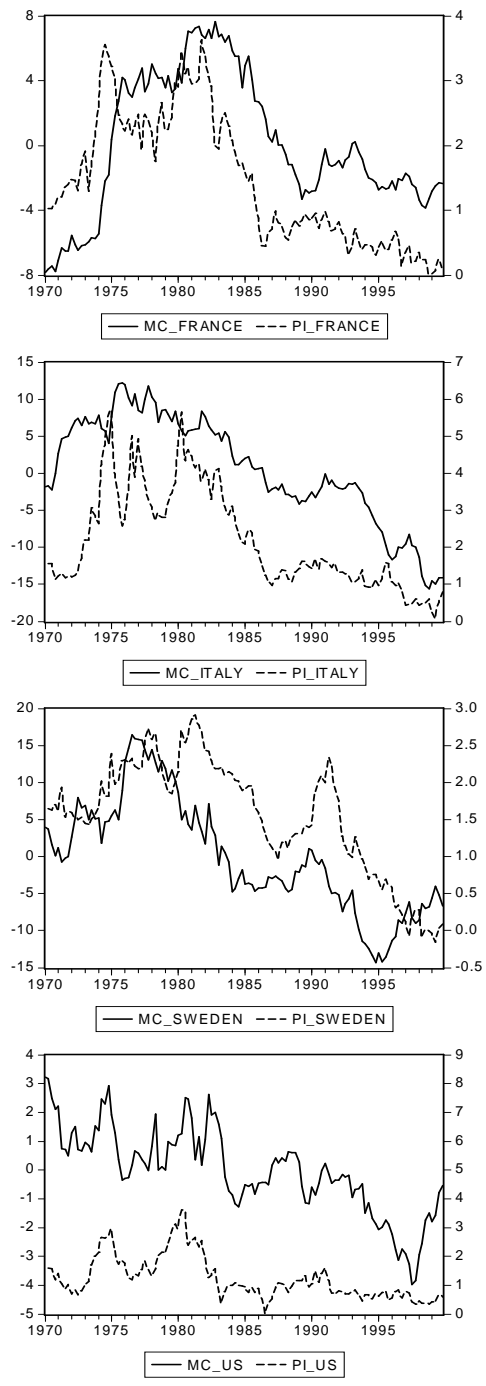
Figure 2: Unit labor cost assuming Cobb-Douglas technology (solide line) vs. CES technology (dashed line).
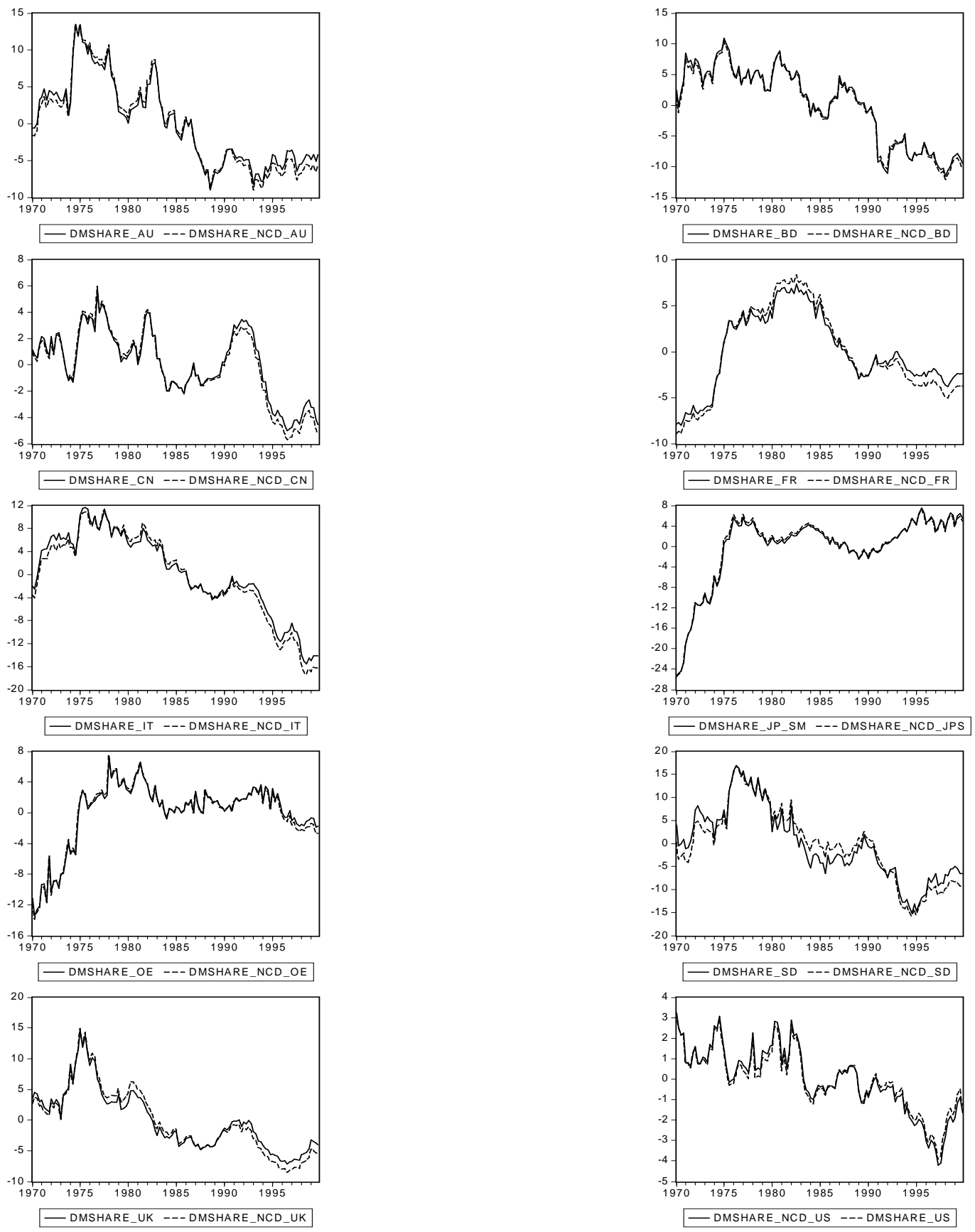
Table 1: GSE reduced form estimates using mean detrended inflation and unit labor cost

\begin{tabular}{|c|c|c|c|c|c|c|c|c|c|c|c|}
\hline Frequ. Range & Parameter & Australia & Austria & Canada & France & Germany & Italy & Japan & Sweden & UK & US \\
\hline \multirow[t]{4}{*}[0;\pi]{} & $\bar{\beta}$ & 0.962 & 1.008 & 0.992 & 0.967 & 0.999 & "1.030 & 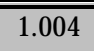 & 1.030 & 0.987 & $\overline{0.976}$ \\
\hline & & 0.019 & 0.019 & 0.009 & 0.006 & 0.015 & 0.012 & 0.014 & 0.028 & 0.019 & 0.013 \\
\hline & $\psi$ & 0.009 & 0.005 & 0.003 & 0.015 & 0.000 & -0.009 & 0.002 & -0.008 & 0.003 & 0.019 \\
\hline & & 0.003 & 0.003 & 0.003 & 0.002 & 0.001 & 0.002 & 0.003 & 0.004 & 0.005 & 0.007 \\
\hline \multirow[t]{4}{*}[0;\pi/3]{} & $\beta$ & 0.970 & 0.924 & 0.978 & 0.965 & 1.005 & 1.021 & 1.019 & 1.026 & 0.946 & 0.973 \\
\hline & & 0.045 & 0.094 & 0.030 & 0.015 & 0.118 & 0.024 & 0.036 & 0.368 & 0.053 & 0.024 \\
\hline & $\psi$ & 0.007 & 0.028 & 0.012 & 0.016 & -0.002 & -0.006 & 0.008 & 0.013 & 0.016 & 0.021 \\
\hline & & 0.008 & 0.011 & 0.010 & 0.004 & 0.010 & 0.005 & 0.006 & 0.028 & 0.014 & 0.013 \\
\hline \multirow[t]{4}{*}[\pi/15;\pi/\beta]{} & $\beta$ & 0.969 & 1.073 & 0.997 & 0.969 & 0.979 & 1.007 & 1.015 & 1.135 & 0.954 & 0.970 \\
\hline & & 0.069 & 0.282 & 0.077 & 0.034 & 0.232 & 0.034 & 0.081 & 0.454 & 0.073 & 0.041 \\
\hline & $\psi$ & 0.007 & 0.054 & 0.017 & 0.021 & -0.011 & -0.002 & 0.013 & 0.027 & 0.023 & 0.036 \\
\hline & & 0.013 & 0.008 & 0.024 & 0.008 & 0.014 & 0.007 & 0.016 & 0.037 & 0.025 & 0.023 \\
\hline \multirow[t]{4}{*}[\pi/15;\pi/4]{} & $\beta$ & 0.970 & 1.051 & 1.036 & 0.978 & 0.951 & 1.003 & 1.024 & 1.148 & 0.955 & 0.972 \\
\hline & & 0.126 & 0.254 & 0.171 & 0.096 & 0.179 & 0.067 & 0.144 & 0.395 & 0.219 & 0.052 \\
\hline & $\psi$ & 0.007 & 0.054 & 0.040 & 0.028 & -0.013 & -0.001 & 0.017 & 0.028 & 0.050 & 0.033 \\
\hline & & 0.023 & 0.017 & 0.030 & 0.017 & 0.011 & 0.012 & 0.027 & 0.032 & 0.063 & 0.029 \\
\hline
\end{tabular}

Table 2: GMM reduced form estimates using mean detrended inflation and unit labor cost

\begin{tabular}{ccccccccccccc}
\hline Parameter & Australia & Austria & Canada & France & Germany & Italy & Japan & Sweden & UK & US \\
\hline \hline$\beta$ & 0.988 & 0.957 & 0.993 & 1.022 & 0.995 & 1.023 & 1.053 & 1.022 & 1.068 & 0.906 \\
& 0.024 & 0.028 & 0.017 & 0.017 & 0.025 & 0.019 & 0.032 & 0.036 & 0.032 & 0.019 \\
$\psi$ & -0.002 & 0.020 & 0.002 & 0.007 & 0.003 & 0.000 & -0.007 & -0.007 & 0.021 & -0.043 \\
& 0.009 & 0.009 & 0.008 & 0.007 & 0.005 & 0.005 & 0.007 & 0.006 & 0.010 & 0.020 \\
\hline J-stat & 5.782 & 12.341 & 6.746 & 6.464 & 9.793 & 6.322 & 8.08 & 6.604 & 7.886 & 13.341 \\
& $(0.672)$ & $(0.137)$ & $(0.564)$ & $(0.595)$ & $(0.280)$ & $(0.611)$ & $(0.426)$ & $(0.580)$ & $(0.445)$ & $(0.101)$ \\
\hline
\end{tabular}

Note: We use 4 lags in inflation and in marginal cost and 2 lags in H-P detrended output as intruments.

$\mathrm{J}$-stasistics and their corresponding $\mathrm{p}$-value (in parenthesis) are also diplayed. 
Table 3: GSE structural estimates using mean detrended inflation and unit labor cost

\begin{tabular}{|c|c|c|c|c|c|c|c|c|c|c|c|}
\hline Frequ. Range & Parameter & Australia & Austria & Canada & France & Germany & Italy & Japan & Sweden & UK & US \\
\hline \multirow[t]{8}{*}[0;\pi]{} & $\beta$ & 0.962 & 1.008 & 0.992 & 0.967 & 0.998 & 0.994 & 1.006 & 0.981 & 0.987 & 0.976 \\
\hline & & 0.019 & 0.019 & 0.008 & 0.006 & 0.012 & 0.007 & 0.013 & 0.018 & 0.019 & 0.012 \\
\hline & $\alpha$ & 0.925 & 1.065 & 0.952 & 0.898 & 1.003 & 1.003 & 1.036 & 1.010 & 0.952 & 0.881 \\
\hline & & 0.013 & 0.021 & 0.018 & 0.005 & 0.028 & 0.017 & 0.032 & 0.028 & 0.035 & 0.018 \\
\hline & $\psi$ & 0.009 & 0.005 & 0.003 & 0.015 & 0.000 & 0.000 & 0.001 & 0.000 & 0.003 & 0.019 \\
\hline & & 0.003 & 0.003 & 0.002 & 0.001 & 0.000 & 0.000 & 0.002 & 0.000 & 0.004 & 0.006 \\
\hline & D & 13.317 & -15.371 & 20.796 & 9.779 & -373.330 & -318.750 & -27.844 & -103.890 & 20.866 & 8.387 \\
\hline & & 2.311 & 5.048 & 7.656 & 0.459 & 3943.500 & 1771.000 & 25.043 & 306.850 & 15.136 & 1.263 \\
\hline \multirow[t]{8}{*}[0;\pi/]{} & $\beta$ & 0.970 & 0.899 & 0.978 & 0.965 & 0.917 & 0.996 & 1.020 & 1.167 & 0.946 & 0.973 \\
\hline & & 0.048 & 0.080 & 0.029 & 0.016 & 0.055 & 0.014 & 0.044 & 0.523 & 0.055 & 0.023 \\
\hline & $\alpha$ & 0.933 & 0.889 & 0.905 & 0.896 & 1.034 & 1.002 & 0.905 & 0.860 & 0.903 & 0.876 \\
\hline & & 0.037 & 0.050 & 0.041 & 0.012 & 0.197 & 0.042 & 0.060 & 0.081 & 0.038 & 0.031 \\
\hline & $\psi$ & 0.007 & 0.025 & 0.012 & 0.016 & -0.002 & 0.000 & 0.008 & 0.000 & 0.016 & 0.021 \\
\hline & & 0.007 & 0.020 & 0.010 & 0.004 & 0.004 & 0.000 & 0.013 & 0.075 & 0.012 & 0.010 \\
\hline & D & 14.969 & 9.024 & 10.547 & 9.648 & -29.773 & -477.610 & 10.502 & 7.130 & 10.272 & 8.065 \\
\hline & & 8.374 & 4.072 & 4.543 & 1.141 & 174.540 & 9561.500 & 6.635 & 4.130 & 4.020 & 1.991 \\
\hline \multirow[t]{8}{*}[\pi/15;\pi/\beta]{} & $\beta$ & 0.969 & 0.872 & 0.997 & 0.968 & 0.891 & 1.002 & 1.015 & 1.139 & 0.954 & 0.969 \\
\hline & & 0.070 & 0.616 & 0.067 & 0.027 & 0.037 & 0.032 & 0.068 & 0.413 & 0.071 & 0.042 \\
\hline & $\alpha$ & 0.932 & 0.864 & 0.880 & 0.877 & 1.055 & 0.999 & 0.885 & 0.790 & 0.877 & 0.836 \\
\hline & & 0.054 & 0.326 & 0.087 & 0.028 & 0.116 & 0.120 & 0.076 & 0.110 & 0.057 & 0.054 \\
\hline & $\psi$ & 0.007 & 0.039 & 0.017 & 0.021 & -0.003 & 0.000 & 0.013 & 0.026 & 0.023 & 0.037 \\
\hline & & 0.011 & 0.174 & 0.027 & 0.010 & 0.002 & 0.000 & 0.021 & 0.100 & 0.022 & 0.026 \\
\hline & D & 14.795 & 7.330 & 8.340 & 8.131 & -18.085 & 1004.600 & 8.705 & 4.771 & 8.147 & 6.110 \\
\hline & & 11.789 & 17.507 & 6.058 & 1.845 & 38.072 & 121020.000 & 5.744 & 2.510 & 3.787 & 2.031 \\
\hline \multirow[t]{8}{*}[\pi/15;\pi/4]{} & $\beta$ & 0.970 & 0.889 & 0.939 & 0.978 & 0.853 & 1.001 & 1.024 & 1.156 & 0.956 & 0.970 \\
\hline & & 0.128 & 0.136 & 0.057 & 0.104 & 0.026 & 0.054 & 0.165 & 0.461 & 0.226 & 0.055 \\
\hline & $\alpha$ & 0.933 & 0.897 & 1.036 & 0.854 & 1.027 & 1.001 & 0.867 & 0.782 & 0.816 & 0.842 \\
\hline & & 0.107 & 0.088 & 0.050 & 0.026 & 0.019 & 0.275 & 0.179 & 0.122 & 0.051 & 0.062 \\
\hline & $\psi$ & 0.007 & 0.023 & -0.001 & 0.028 & -0.003 & 0.000 & 0.017 & 0.027 & 0.050 & 0.034 \\
\hline & & 0.021 & 0.034 & 0.002 & 0.018 & 0.002 & 0.001 & 0.059 & 0.117 & 0.050 & 0.028 \\
\hline & D & 15.011 & 9.737 & -27.398 & 6.840 & -37.228 & -723.380 & 7.534 & 4.582 & 5.441 & 6.334 \\
\hline & & 24.096 & 8.351 & 37.275 & 1.215 & 26.739 & 143870.000 & 10.159 & 2.568 & 1.520 & 2.469 \\
\hline
\end{tabular}


Table 4: GSE structural estimates using H-P detrended inflation and unit labor cost

\begin{tabular}{|c|c|c|c|c|c|c|c|c|c|c|}
\hline Parameter & Australia & Austria & Canada & France & Germany & Italy & Japan & Sweden & UK & US \\
\hline \multirow[t]{2}{*}{$\beta$} & 0.982 & $\overline{c 1.038}$ & 0.999 & 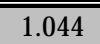 & 0.999 & $\bar{~} 1.002$ & 1.001 & 0.992 & 0.992 & 0.992 \\
\hline & 0.030 & 0.037 & 0.025 & 0.021 & 0.025 & 0.020 & 0.025 & 0.050 & 0.022 & 0.020 \\
\hline \multirow[t]{2}{*}{$\alpha$} & 0.795 & 0.750 & 0.923 & 0.750 & 0.923 & 0.999 & 0.999 & 1.004 & 0.928 & 0.823 \\
\hline & 0.016 & 0.021 & 0.026 & 0.014 & 0.026 & 0.033 & 0.074 & 0.041 & 0.058 & 0.023 \\
\hline \multirow[t]{2}{*}{$\psi$} & 0.056 & 0.074 & 0.007 & 0.072 & 0.007 & 0.000 & 0.000 & 0.000 & 0.006 & 0.039 \\
\hline & 0.012 & 0.018 & 0.005 & 0.011 & 0.005 & 0.000 & 0.000 & 0.000 & 0.010 & 0.012 \\
\hline \multirow[t]{2}{*}{ D } & 4.888 & 4.003 & 12.911 & 4.007 & 12.911 & 914.190 & 1532.800 & -251.170 & 13.888 & 5.650 \\
\hline & 0.390 & 0.343 & 4.281 & 0.220 & 4.281 & 27427.000 & 174070.000 & 2615.400 & 11.102 & 0.745 \\
\hline
\end{tabular}

Table 5: Generalized Spectral Estimates using mean detrended inflation and unit labor cost with CES technology

\begin{tabular}{|c|c|c|c|c|c|c|c|c|c|c|c|}
\hline Frequ. Range & & Australia & Austria & Canada & France & Germany & Italy & Japan & Sweden & UK & US \\
\hline \multirow[t]{4}{*}[0;\pi]{} & $\beta$ & 1.008 & 1.006 & 0.990 & 0.964 & 0.999 & 1.016 & 1.004 & 1.028 & 0.965 & 0.973 \\
\hline & & 0.020 & 0.018 & 0.010 & 0.006 & 0.015 & 0.012 & 0.014 & 0.032 & 0.019 & 0.012 \\
\hline & $\psi$ & 0.005 & 0.004 & 0.003 & 0.013 & 0.000 & -0.005 & 0.002 & -0.007 & 0.009 & 0.018 \\
\hline & & 0.003 & 0.003 & 0.003 & 0.001 & 0.001 & 0.002 & 0.002 & 0.004 & 0.005 & 0.006 \\
\hline \multirow[t]{4}{*}[0;\pi/]{} & $\beta$ & 1.007 & 1.089 & 0.974 & 0.963 & 1.005 & 1.007 & 1.018 & 0.900 & 0.924 & 0.972 \\
\hline & & 0.047 & 0.111 & 0.031 & 0.015 & 0.120 & 0.025 & 0.036 & 0.568 & 0.056 & 0.025 \\
\hline & $\psi$ & 0.007 & 0.036 & 0.012 & 0.013 & -0.002 & -0.002 & 0.008 & -0.010 & 0.020 & 0.019 \\
\hline & & 0.006 & 0.005 & 0.010 & 0.003 & 0.010 & 0.004 & 0.006 & 0.072 & 0.014 & 0.012 \\
\hline
\end{tabular}


Table 7: GMM reduced form estimates for hybrid Phillips curve using mean detrended inflation and unit labor cost

\begin{tabular}{ccccccccccc}
\hline Parameter & Australia & Austria & Canada & France & Germany & Italy & Japan & Sweden & UK & US \\
\hline \hline gamma_b & 0.224 & 0.251 & 0.289 & 0.333 & 0.163 & 0.457 & 0.194 & -0.059 & 0.364 & 0.413 \\
& 0.091 & 0.074 & 0.077 & 0.092 & 0.055 & 0.060 & 0.075 & 0.080 & 0.057 & 0.055 \\
gamma_f & 0.758 & 0.706 & 0.709 & 0.668 & 0.844 & 0.541 & 0.798 & 1.081 & 0.628 & 0.563 \\
& 0.098 & 0.075 & 0.078 & 0.092 & 0.060 & 0.059 & 0.102 & 0.092 & 0.062 & 0.055 \\
$\psi$ & -0.003 & 0.016 & 0.001 & 0.003 & -0.001 & 0.000 & 0.003 & -0.007 & -0.002 & -0.010 \\
& 0.007 & 0.009 & 0.006 & 0.005 & 0.004 & 0.003 & 0.006 & 0.007 & 0.006 & 0.013 \\
\hline J-stat & 5.003 & 11.506 & 4.242 & 3.636 & 8.531 & 4.246 & 6.744 & 6.319 & 5.669 & 8.849 \\
& $(0.660)$ & $(0.118)$ & $(0.752)$ & $(0.821)$ & $(0.288)$ & $(0.751)$ & $(0.456)$ & $(0.503)$ & $(0.579)$ & $(0.264)$ \\
\hline
\end{tabular}

Note: We use 4 lags in inflation and in marginal cost and 2 lags in H-P detrended output as intruments.

J-stasistics and their corresponding p-value (in parenthesis) are also diplayed.

Table 9: GMM reduced form estimates for hybrid Phillips curve using mean detrended inflation and H-P detrended output

\begin{tabular}{ccccccccccc}
\hline Parameter & Australia & Austria & Canada & France & Germany & Italy & Japan & Sweden & UK & US \\
\hline \hline gamma_b & 0.228 & 0.256 & 0.294 & 0.356 & 0.161 & 0.455 & 0.203 & -0.058 & 0.322 & 0.422 \\
& 0.093 & 0.071 & 0.074 & 0.083 & 0.055 & 0.060 & 0.081 & 0.081 & 0.052 & 0.055 \\
gamma_f & 0.757 & 0.733 & 0.707 & 0.646 & 0.840 & 0.544 & 0.791 & 1.059 & 0.671 & 0.560 \\
& 0.100 & 0.080 & 0.076 & 0.083 & 0.059 & 0.061 & 0.110 & 0.091 & 0.059 & 0.056 \\
$\psi$ & 0.001 & 0.028 & 0.003 & -0.001 & 0.004 & -0.002 & -0.002 & -0.028 & 0.007 & -0.008 \\
& 0.003 & 0.019 & 0.005 & 0.001 & 0.005 & 0.007 & 0.005 & 0.022 & 0.005 & 0.007 \\
\hline J-stat & 5.110 & 11.977 & 3.985 & 3.590 & 8.347 & 4.197 & 6.746 & 5.866 & 4.435 & 8.924 \\
& $(0.647)$ & $(0.101)$ & $(0.781)$ & $(0.826)$ & $(0.303)$ & $(0.757)$ & $(0.456)$ & $(0.555)$ & $(0.729)$ & $(0.258)$ \\
\hline
\end{tabular}

Note: We use 4 lags in inflation and in marginal cost and 2 lags in H-P detrended output as intruments.

$\mathrm{J}$-stasistics and their corresponding $\mathrm{p}$-value (in parenthesis) are also diplayed. 
Table 6: GSE structural estimates hybrid Phillips curve using mean detrended inflation and unit labor cost

\begin{tabular}{|c|c|c|c|c|c|c|}
\hline Freq. Range & Parameter & Australia & Austria & Canada & France & Germany \\
\hline \multirow[t]{14}{*}[0;\pi]{} & / $\beta$ & 1.025 & 1.116 & 1.068 & " 1.043 & 1.090 \\
\hline & & 0.008 & 0.029 & 0.014 & 0.010 & 0.013 \\
\hline & $\alpha$ & 0.843 & 0.814 & 0.848 & 0.871 & 0.841 \\
\hline & & 0.035 & 0.056 & 0.044 & 0.041 & 0.031 \\
\hline & $\omega$ & 0.712 & 0.855 & 0.885 & 0.889 & 0.860 \\
\hline & & 0.022 & 0.064 & 0.049 & 0.049 & 0.035 \\
\hline & $\psi$ & 0.004 & 0.001 & 0.001 & 0.001 & 0.001 \\
\hline & & 0.002 & 0.002 & 0.001 & 0.001 & 0.001 \\
\hline & gamma_b & 0.551 & 0.520 & 0.507 & 0.507 & 0.519 \\
\hline & & 0.013 & 0.028 & 0.020 & 0.019 & 0.015 \\
\hline & gamma_f & 0.453 & 0.488 & 0.496 & 0.496 & 0.487 \\
\hline & & 0.013 & 0.025 & 0.019 & 0.018 & 0.013 \\
\hline & D & 6.388 & 5.391 & 6.571 & 7.761 & 6.300 \\
\hline & & 1.425 & 1.625 & 1.882 & 2.457 & 1.242 \\
\hline \multirow[t]{14}{*}[0;\pi/3]{} & $\beta$ & 0.990 & 1.000 & 0.984 & 1.001 & 1.015 \\
\hline & & 0.002 & 0.002 & 0.002 & 0.002 & 0.002 \\
\hline & $\alpha$ & 0.690 & 0.670 & 0.676 & 0.741 & 0.768 \\
\hline & & 0.008 & 0.008 & 0.010 & 0.008 & 0.007 \\
\hline & $\omega$ & 0.617 & 0.604 & 0.604 & 0.643 & 0.669 \\
\hline & & 0.005 & 0.005 & 0.006 & 0.005 & 0.005 \\
\hline & $\psi$ & 0.029 & 0.034 & 0.034 & 0.017 & 0.012 \\
\hline & & 0.002 & 0.002 & 0.002 & 0.001 & 0.001 \\
\hline & gamma_b & 0.524 & 0.526 & 0.522 & 0.536 & 0.539 \\
\hline & & 0.004 & 0.004 & 0.004 & 0.003 & 0.003 \\
\hline & gamma_f & 0.474 & 0.474 & 0.474 & 0.464 & 0.463 \\
\hline & & 0.004 & 0.004 & 0.004 & 0.003 & 0.003 \\
\hline & D & 3.223 & 3.032 & 3.085 & 3.868 & 4.308 \\
\hline & & 0.088 & 0.075 & 0.093 & 0.126 & 0.136 \\
\hline \multirow[t]{14}{*}[\pi/15;\pi/\beta]{} & $\bar{\beta}$ & 0.977 & 0.982 & 0.983 & 0.997 & 1.003 \\
\hline & & 0.002 & 0.002 & 0.003 & 0.003 & 0.002 \\
\hline & $\alpha$ & 0.613 & 0.614 & 0.624 & 0.684 & 0.705 \\
\hline & & 0.010 & 0.009 & 0.011 & 0.010 & 0.009 \\
\hline & $\omega$ & 0.566 & 0.569 & 0.570 & 0.603 & 0.631 \\
\hline & & 0.006 & 0.005 & 0.006 & 0.006 & 0.006 \\
\hline & $\psi$ & 0.057 & 0.056 & 0.053 & 0.031 & 0.024 \\
\hline & & 0.004 & 0.003 & 0.004 & 0.002 & 0.002 \\
\hline & gamma_b & 0.512 & 0.512 & 0.516 & 0.530 & 0.529 \\
\hline & & 0.005 & 0.004 & 0.005 & 0.004 & 0.004 \\
\hline & gamma_f & 0.483 & 0.484 & 0.480 & 0.469 & 0.472 \\
\hline & & 0.005 & 0.004 & 0.005 & 0.004 & 0.004 \\
\hline & D & 2.587 & 2.588 & 2.658 & 3.163 & 3.393 \\
\hline & & 0.068 & 0.058 & 0.076 & 0.099 & 0.102 \\
\hline \multirow[t]{14}{*}[\pi/15;\pi/4]{} & $\beta$ & 0.978 & 0.984 & 0.983 & 0.996 & 1.003 \\
\hline & & 0.003 & 0.003 & 0.003 & 0.003 & 0.003 \\
\hline & $\alpha$ & 0.622 & 0.621 & 0.627 & 0.686 & 0.710 \\
\hline & & 0.012 & 0.012 & 0.012 & 0.011 & 0.010 \\
\hline & $\omega$ & 0.571 & 0.573 & 0.572 & 0.605 & 0.633 \\
\hline & & 0.007 & 0.007 & 0.007 & 0.006 & 0.006 \\
\hline & $\psi$ & 0.054 & 0.053 & 0.051 & 0.031 & 0.023 \\
\hline & & 0.004 & 0.004 & 0.004 & 0.002 & 0.002 \\
\hline & gamma_b & 0.513 & 0.514 & 0.517 & 0.530 & 0.530 \\
\hline & & 0.006 & 0.006 & 0.006 & 0.005 & 0.005 \\
\hline & gamma_f & 0.482 & 0.482 & 0.479 & 0.469 & 0.471 \\
\hline & & 0.006 & 0.006 & 0.006 & 0.005 & 0.004 \\
\hline & $\mathrm{D}$ & 2.642 & 2.639 & 2.682 & 3.181 & 3.445 \\
\hline & & 0.086 & 0.081 & 0.089 & 0.112 & 0.121 \\
\hline
\end{tabular}


Table 6bis: GSE structural estimates hybrid Phillips curve using mean detrended inflation and unit labor cost

\begin{tabular}{|c|c|c|c|c|c|c|}
\hline Freq. Range & Parameter & Italy & Japan & Sweden & UK & US \\
\hline \multirow{14}{*}[0;\pi]{} & $\beta$ & 1.056 & 1.048 & 1.069 & 1.066 & 1.052 \\
\hline & & 0.013 & 0.006 & 0.018 & 0.019 & 0.015 \\
\hline & $\alpha$ & 0.879 & 0.796 & 0.854 & 0.840 & 0.867 \\
\hline & & 0.051 & 0.019 & 0.063 & 0.067 & 0.057 \\
\hline & $\omega$ & 0.910 & 0.678 & 0.910 & 0.872 & 0.909 \\
\hline & & 0.060 & 0.012 & 0.074 & 0.061 & 0.062 \\
\hline & $\psi$ & 0.000 & 0.007 & 0.001 & 0.001 & 0.001 \\
\hline & & 0.001 & 0.002 & 0.001 & 0.002 & 0.001 \\
\hline & gamma_b & 0.506 & 0.556 & 0.502 & 0.508 & 0.502 \\
\hline & & 0.023 & 0.008 & 0.029 & 0.028 & 0.024 \\
\hline & gamma_f & 0.496 & 0.452 & 0.501 & 0.496 & 0.500 \\
\hline & & 0.022 & 0.007 & 0.027 & 0.026 & 0.023 \\
\hline & D & 8.297 & 4.892 & 6.836 & 6.246 & 7.541 \\
\hline & & 3.531 & 0.466 & 2.927 & 2.594 & 3.215 \\
\hline \multirow[t]{14}{*}[0;\pi/3]{} & $\bar{\beta}$ & 0.998 & 1.008 & 0.997 & 0.980 & 0.964 \\
\hline & & 0.002 & 0.003 & 0.002 & 0.002 & 0.001 \\
\hline & $\alpha$ & 0.749 & 0.677 & 0.702 & 0.673 & 0.610 \\
\hline & & 0.009 & 0.008 & 0.009 & 0.010 & 0.011 \\
\hline & $\omega$ & 0.655 & 0.606 & 0.627 & 0.605 & 0.564 \\
\hline & & 0.006 & 0.005 & 0.005 & 0.006 & 0.007 \\
\hline & $\psi$ & 0.016 & 0.031 & 0.025 & 0.035 & 0.060 \\
\hline & & 0.001 & 0.002 & 0.002 & 0.002 & 0.004 \\
\hline & gamma_b & 0.533 & 0.531 & 0.527 & 0.519 & 0.506 \\
\hline & & 0.004 & 0.004 & 0.004 & 0.005 & 0.005 \\
\hline & gamma_f & 0.467 & 0.471 & 0.472 & 0.476 & 0.486 \\
\hline & & 0.004 & 0.004 & 0.004 & 0.005 & 0.005 \\
\hline & $\mathrm{D}$ & 3.980 & 3.095 & 3.356 & 3.058 & 2.562 \\
\hline & & 0.144 & 0.077 & 0.097 & 0.095 & 0.073 \\
\hline \multirow[t]{14}{*}[\pi/15;\pi/\beta]{} & $\bar{\beta}$ & 0.994 & 0.990 & 0.980 & 0.968 & 0.957 \\
\hline & & 0.003 & 0.003 & 0.003 & 0.002 & 0.002 \\
\hline & $\alpha$ & 0.684 & 0.631 & 0.624 & 0.596 & 0.535 \\
\hline & & 0.011 & 0.010 & 0.010 & 0.012 & 0.012 \\
\hline & $\omega$ & 0.613 & 0.575 & 0.579 & 0.556 & 0.519 \\
\hline & & 0.007 & 0.006 & 0.007 & 0.007 & 0.007 \\
\hline & $\psi$ & 0.030 & 0.049 & 0.051 & 0.067 & 0.105 \\
\hline & & 0.003 & 0.003 & 0.003 & 0.005 & 0.007 \\
\hline & gamma_b & 0.525 & 0.520 & 0.511 & 0.506 & 0.491 \\
\hline & & 0.005 & 0.005 & 0.005 & 0.006 & 0.006 \\
\hline & gamma_f & 0.474 & 0.478 & 0.484 & 0.487 & 0.498 \\
\hline & & 0.005 & 0.005 & 0.005 & 0.006 & 0.007 \\
\hline & D & 3.163 & 2.711 & 2.660 & 2.474 & 2.149 \\
\hline & & 0.113 & 0.073 & 0.074 & 0.072 & 0.057 \\
\hline \multirow[t]{14}{*}[\pi/15;\pi/4]{} & $\bar{\beta}$ & 0.992 & 0.992 & 0.982 & 0.969 & 0.957 \\
\hline & & 0.003 & 0.004 & 0.003 & 0.002 & 0.003 \\
\hline & $\alpha$ & 0.684 & 0.636 & 0.633 & 0.600 & 0.539 \\
\hline & & 0.012 & 0.012 & 0.012 & 0.013 & 0.015 \\
\hline & $\omega$ & 0.613 & 0.578 & 0.584 & 0.558 & 0.522 \\
\hline & & 0.008 & 0.007 & 0.008 & 0.008 & 0.008 \\
\hline & $\psi$ & 0.030 & 0.047 & 0.048 & 0.065 & 0.101 \\
\hline & & 0.003 & 0.004 & 0.004 & 0.005 & 0.008 \\
\hline & gamma_b & 0.524 & 0.521 & 0.513 & 0.507 & 0.492 \\
\hline & & 0.006 & 0.006 & 0.006 & 0.006 & 0.008 \\
\hline & gamma_f & 0.474 & 0.477 & 0.483 & 0.486 & 0.498 \\
\hline & & 0.005 & 0.005 & 0.006 & 0.007 & 0.008 \\
\hline & D & 3.163 & 2.751 & 2.723 & 2.499 & 2.171 \\
\hline & & 0.124 & 0.089 & 0.092 & 0.083 & 0.069 \\
\hline
\end{tabular}


Table 8: GSE structural estimates hybrid Phillips curve using mean detrended inflation and H-P detrended output

\begin{tabular}{|c|c|c|c|c|c|c|}
\hline Freq. Range & Parameter & Australia & Austria & Canada & France & Germany \\
\hline \multirow[t]{14}{*}{ 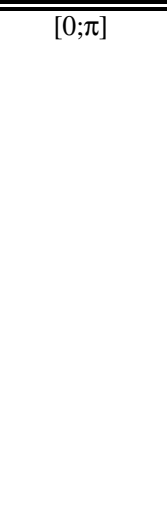 } & / $\beta$ & 1.116 & 1.113 & 1.112 & 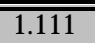 & 1.099 \\
\hline & & 0.026 & 0.037 & 0.022 & 0.022 & 0.021 \\
\hline & $\alpha$ & 0.799 & 0.744 & 0.695 & 0.762 & 0.831 \\
\hline & & 0.054 & 0.074 & 0.028 & 0.036 & 0.045 \\
\hline & $\omega$ & 0.848 & 0.831 & 0.771 & 0.818 & 0.857 \\
\hline & & 0.059 & 0.062 & 0.032 & 0.051 & 0.047 \\
\hline & $\psi$ & 0.002 & 0.005 & 0.010 & 0.004 & 0.001 \\
\hline & & 0.002 & 0.004 & 0.003 & 0.002 & 0.001 \\
\hline & gamma_b & 0.517 & 0.504 & 0.507 & 0.513 & 0.519 \\
\hline & & 0.027 & 0.034 & 0.017 & 0.022 & 0.021 \\
\hline & gamma_f & 0.492 & 0.505 & 0.505 & 0.496 & 0.487 \\
\hline & & 0.024 & 0.031 & 0.014 & 0.019 & 0.019 \\
\hline & D & 4.967 & 3.902 & 3.276 & 4.205 & 5.904 \\
\hline & & 1.332 & 1.128 & 0.300 & 0.645 & 1.554 \\
\hline \multirow[t]{14}{*}[0;\pi/3]{} & $\beta$ & 0.971 & 0.940 & 0.983 & 0.989 & 0.974 \\
\hline & & 0.003 & 0.003 & 0.003 & 0.004 & 0.002 \\
\hline & $\alpha$ & 0.573 & 0.461 & 0.624 & 0.601 & 0.611 \\
\hline & & 0.010 & 0.013 & 0.010 & 0.011 & 0.010 \\
\hline & $\omega$ & 0.542 & 0.479 & 0.575 & 0.562 & 0.572 \\
\hline & & 0.006 & 0.007 & 0.006 & 0.007 & 0.007 \\
\hline & $\psi$ & 0.079 & 0.172 & 0.052 & 0.061 & 0.057 \\
\hline & & 0.005 & 0.011 & 0.003 & 0.004 & 0.004 \\
\hline & gamma_b & 0.503 & 0.468 & 0.514 & 0.513 & 0.507 \\
\hline & & 0.005 & 0.008 & 0.005 & 0.006 & 0.005 \\
\hline & gamma_f & 0.490 & 0.517 & 0.482 & 0.484 & 0.487 \\
\hline & & 0.005 & 0.008 & 0.005 & 0.006 & 0.005 \\
\hline & D & 2.341 & 1.855 & 2.663 & 2.507 & 2.574 \\
\hline & & 0.056 & 0.044 & 0.074 & 0.072 & 0.069 \\
\hline \multirow[t]{14}{*}[\pi/15;\pi/\beta]{} & $\bar{\beta}$ & 0.965 & 0.935 & 0.979 & 0.976 & 0.972 \\
\hline & & 0.003 & 0.003 & 0.003 & 0.004 & 0.002 \\
\hline & $\alpha$ & 0.555 & 0.444 & 0.612 & 0.580 & 0.594 \\
\hline & & 0.010 & 0.013 & 0.010 & 0.012 & 0.010 \\
\hline & $\omega$ & 0.532 & 0.468 & 0.568 & 0.547 & 0.561 \\
\hline & & 0.006 & 0.007 & 0.006 & 0.007 & 0.007 \\
\hline & $\psi$ & 0.090 & 0.192 & 0.057 & 0.074 & 0.066 \\
\hline & & 0.005 & 0.012 & 0.004 & 0.005 & 0.004 \\
\hline & gamma_b & 0.497 & 0.462 & 0.511 & 0.505 & 0.504 \\
\hline & & 0.005 & 0.008 & 0.005 & 0.006 & 0.005 \\
\hline & gamma_f & 0.494 & 0.521 & 0.485 & 0.489 & 0.490 \\
\hline & & 0.006 & 0.008 & 0.005 & 0.006 & 0.005 \\
\hline & D & 2.249 & 1.798 & 2.578 & 2.378 & 2.463 \\
\hline & & 0.052 & 0.041 & 0.070 & 0.068 & 0.063 \\
\hline \multirow[t]{14}{*}[\pi/15;\pi/4]{} & $\beta$ & 0.967 & 0.936 & 0.978 & 0.974 & 0.973 \\
\hline & & 0.004 & 0.004 & 0.003 & 0.004 & 0.003 \\
\hline & $\alpha$ & 0.560 & 0.446 & 0.611 & 0.576 & 0.598 \\
\hline & & 0.013 & 0.016 & 0.012 & 0.014 & 0.012 \\
\hline & $\omega$ & 0.535 & 0.470 & 0.568 & 0.546 & 0.564 \\
\hline & & 0.007 & 0.009 & 0.007 & 0.008 & 0.008 \\
\hline & $\psi$ & 0.086 & 0.189 & 0.058 & 0.076 & 0.064 \\
\hline & & 0.006 & 0.015 & 0.004 & 0.006 & 0.005 \\
\hline & gamma_b & 0.499 & 0.463 & 0.510 & 0.504 & 0.505 \\
\hline & & 0.007 & 0.010 & 0.006 & 0.007 & 0.006 \\
\hline & gamma_f & 0.493 & 0.520 & 0.485 & 0.490 & 0.489 \\
\hline & & 0.007 & 0.010 & 0.006 & 0.007 & 0.006 \\
\hline & $\mathrm{D}$ & 2.274 & 1.806 & 2.568 & 2.358 & 2.486 \\
\hline & & 0.066 & 0.054 & 0.080 & 0.077 & 0.077 \\
\hline
\end{tabular}


Table 8bis: GSE structural estimates hybrid Phillips curve using mean detrended inflation and H-P detrended output

\begin{tabular}{|c|c|c|c|c|c|c|}
\hline Freq. Range & Parameter & Italy & Japan & Sweden & UK & US \\
\hline \multirow[t]{11}{*}[0;\pi]{} & $\bar{\beta}$ & $\overline{1.033}$ & 1.194 & 0.989 & 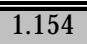 & $\overline{\overline{1.076}}$ \\
\hline & & 0.008 & 0.051 & 0.013 & 0.038 & 0.021 \\
\hline & $\alpha$ & 0.741 & 0.792 & 0.559 & 0.685 & 0.665 \\
\hline & & 0.022 & 0.045 & 0.019 & 0.036 & 0.036 \\
\hline & $\omega$ & 0.632 & 0.785 & 0.561 & 0.765 & 0.765 \\
\hline & & 0.012 & 0.056 & 0.020 & 0.048 & 0.043 \\
\hline & & 0.003 & 0.002 & 0.010 & 0.005 & 0.005 \\
\hline & gamma_b & 0.551 & 0.557 & 0.495 & 0.516 & 0.487 \\
\hline & & 0.009 & 0.029 & 0.013 & 0.025 & 0.021 \\
\hline & gamma_f & 0.455 & 0.463 & 0.502 & 0.500 & 0.521 \\
\hline & & 0.009 & 0.022 & 0.012 & 0.020 & 0.019 \\
\hline \multirow{9}{*}[0;\pi/3]{} & $\alpha$ & 0.604 & 0.562 & 0.453 & 0.569 & 0.555 \\
\hline & & 0.009 & 0.014 & 0.012 & 0.012 & 0.010 \\
\hline & $\omega$ & 0.559 & 0.530 & 0.468 & 0.536 & 0.536 \\
\hline & & 0.005 & 0.007 & 0.008 & 0.006 & 0.007 \\
\hline & $\psi$ & 0.061 & 0.087 & 0.184 & 0.081 & 0.089 \\
\hline & & 0.003 & 0.007 & 0.011 & 0.005 & 0.005 \\
\hline & gamma_b & 0.514 & 0.503 & 0.469 & 0.505 & 0.495 \\
\hline & & 0.004 & 0.007 & 0.008 & 0.006 & 0.006 \\
\hline & gamma_f & 0.483 & 0.490 & 0.515 & 0.489 & 0.496 \\
\hline \multirow{10}{*}[\pi/15;\pi/3]{} & $\omega$ & 0.548 & 0.521 & 0.456 & 0.520 & 0.525 \\
\hline & & 0.005 & 0.007 & 0.008 & 0.006 & 0.007 \\
\hline & $\psi$ & 0.070 & 0.099 & 0.207 & 0.101 & 0.101 \\
\hline & & 0.004 & 0.007 & 0.012 & 0.006 & 0.006 \\
\hline & gamma_b & 0.509 & 0.496 & 0.463 & 0.495 & 0.490 \\
\hline & & 0.005 & 0.007 & 0.008 & 0.006 & 0.006 \\
\hline & gamma_f & 0.485 & 0.494 & 0.519 & 0.495 & 0.499 \\
\hline & & 0.005 & 0.007 & 0.008 & 0.006 & 0.006 \\
\hline & D & 2.433 & 2.192 & 1.773 & 2.174 & 2.167 \\
\hline & & 0.055 & 0.067 & 0.038 & 0.056 & 0.048 \\
\hline \multirow[t]{10}{*}[\pi/15;\pi/4]{} & $\beta$ & 0.976 & 0.963 & 0.937 & 0.963 & 0.958 \\
\hline & & 0.003 & 0.005 & 0.003 & 0.004 & 0.003 \\
\hline & $\alpha$ & 0.589 & 0.546 & 0.441 & 0.542 & 0.540 \\
\hline & & 0.011 & 0.017 & 0.015 & 0.014 & 0.013 \\
\hline & $\omega$ & 0.548 & 0.522 & 0.461 & 0.521 & 0.526 \\
\hline & & 0.006 & 0.008 & 0.010 & 0.007 & 0.008 \\
\hline & $\psi$ & 0.070 & 0.098 & 0.199 & 0.100 & 0.100 \\
\hline & & 0.005 & 0.009 & 0.015 & 0.008 & 0.007 \\
\hline & gamma_b & 0.509 & 0.497 & 0.465 & 0.496 & 0.491 \\
\hline & & 0.005 & 0.009 & 0.010 & 0.007 & 0.007 \\
\hline
\end{tabular}

